\title{
Viscosity Contrast Effects on the Structure - Property Relationship of Multilayer Soft Film/Foams
}

\author{
Md. Arifur Rahman*, Ricardo Andrade, João Maia, Eric Baer
}

Center for Layered Polymeric Systems, Department of Macromolecular Science and Engineering, Case Western Reserve University, Cleveland, OH 44106-7202, USA

\begin{abstract}
In this research work, multilayer soft film/foam systems based on low-density polyethylene (LDPE) have been developed. In order to improve the layer stability during processing, a viscosity contrast between film and foam layer polymers is maintained. Three different LDPE grades having different melt flow indices were used and film/foam systems with up to 32 layers were produced. High-viscosity film layer and low-viscosity foam layer in each film/foam system contributed to good layer integrity even with high foam content. Measurements of cell density and cell size distribution indicated that high viscosity film layer and increasing layer number have significant confinement effect that enhanced the cell nucleation and suppressed the cell coalescence and thus contributed to single cell arrays in foam layers. Constrained cell growth was observed in 16 and 32 layers film/foam systems. Confinement effect from the high viscosity film layer was also observed at higher foam content. In addition, uniform layer integrity resulted from high viscosity contrast between film and foam layers contributed to higher deformability. Moreover, increasing layer number also improved the tensile modulus and strength of each film/foam system.
\end{abstract}

Keywords: Multilayer coextrusion, soft film/foam, low-density polyethylene, viscosity contrast. 
Correspondence to: Md. Arifur Rahman (arifrahman83@gmail.com)

\section{Introduction}

Polyethylene (PE) foams are widely used polymeric materials. Most of the polyethylene foams possess closed cell structure that makes them suitable for applications where buoyancy, insulation or resiliency are crucial [1,2]. PE foams have wide areas of applications such as in packaging, sports and leisure, toys, insulation, automotive, military, aircraft, buoyancy, cushioning and others. This wide range of application resulted from the efforts to vary properties from hard and tough through to soft and resilient. PE foams possess advantages such as low cost and better toughness in tension over other thermoplastic foams $[3,4]$ and sometimes have the ability to replace foams made from other polymers.

There are several processing technologies that enable the production of closed cell PE foams. Several studies have focused on the processing mechanisms [5-8], morphology, mechanical properties, correlation between cell morphology and foam properties [9-11]. In addition, a number of research works have been carried out to improve the performance of PE foams such as by adding small amounts of micro or nano particles [12-16] or by sandwiching them in between two rigid polymers [17-19]. Such PE foam composites exhibited improved thermal and mechanical behavior [12-19]. However, most of the PE foams that have been commercialized lack high physical strength at relatively low bulk density. Many of them are inadequate for structural applications where they are subjected to impact, tension or vibration. Most of them must be affixed by means of adhesives or like techniques wherein the load is distributed over a relatively broad area. Moreover, when subjected to undue stress, the foams frequently crack and the crack propagates to rapidly result in failure of the element. A novel architecture like layered 
film/foam can be a good alternative to resolve such problems associated with the conventional PE foams [20].

Multilayer film/foam structures are assemblies of alternating film and foam layers, which multilayer coextrusion technology can produce. The novelty of such structure is combining the physical and mechanical behaviors of both solid and foamed polymers. It should be mentioned here that very few works have been reported on the structure-property relationships of coextruded multilayer film/foams. Chisholm and Schrenk first developed the idea of producing foam-film composite laminates by coextrusion [20]. They developed the coextrusion technique to produce multilayer structures with alternating foamed and unfoamed layers, which was highly resistant to shear failure, was puncture resistant, tough and showed improved impact resistance. Several other attempts have been made, such as the works done by Dukess [21] and Kelch [22] in1976 and 1989, respectively. Dukess et al. reported a coextrusion method for the production of a plastic sandwich element made of foam core in between solid plastic skin layers [21]. However, the method was only suitable for the production of laminates with a single foam layer. Kelch [22], also developed a technique for the coextrusion of multilayer foamed film systems that were composed of either two or three foamed layers. Investigators at the DOW Chemical Company developed several products made of multilayer foamed systems [19, 23].

Recently, Baer et al. [24-35] reported a miniaturized multilayer coextrusion technique. Such multilayer coextrusion represents an advanced polymer processing technique that combines two or more polymers in a layered configuration with controlled architecture. This continuous processing technique is capable of economically producing films with up to thousands of layers with individual layer thicknesses from the micro- to the nanoscale [30-35]. Baer et al. reported the development of microlayered film/foam in 2004 [35]. They developed polypropolene (PP) 
based film/foam structures having 8 to 64 layers. They showed that the foam/film structure of natural cork can be replicated synthetically by using the microlayer coextrusion technology. They optimized different processing variables, such as layer numbers, and chemical blowing agent concentrations in order to obtaining good multilayered film/foam systems. With the optimum blowing agent concentration, the cell size can be significantly reduced $(30 \mu \mathrm{m})$ for the polypropylene film/foam systems by increasing the number of layers. Mechanical properties also improved with the increase of layer numbers [34].

As mentioned earlier, previous works $[19,34]$ on multilayer film/foams were concerned with the development and characterization of multilayer film/foams. This research work aims at developing a strategy to improve the layer integrity in multilayer film/foam polyethylene systems. For the first time, a viscosity contrast or viscosity mismatch between film and foam layer polymers has been maintained in order to achieve film/foam multilayer structures with more uniform layer integrity. In addition, more in-depth discussion is given to elucidate the effect of such viscosity contrast on the confinement of cells in foam layers. The effect of structural integrity on the mechanical behavior of multilayer film/foam systems is discussed in detail.

\section{Experimental}

\subsection{Materials and production of multilayer Film/Foam}

Three different grades of low-density polyethylene (LDPE) were used for the fabrication of multilayer film/foam systems. LDPE 5011, LDPE 50041 and LDPE 722 with melt flow indices of $1.9,4.2$ and $8.0 \mathrm{~g} / 10 \mathrm{~min}\left(190{ }^{\circ} \mathrm{C} / 2.16 \mathrm{~kg}\right)$, respectively, were kindly supplied by the Dow 
Chemical Company. Table 1 reports the thermal and physical properties of each LDPE grade. Polypropylene (Daploy WB140 HMS), with a melt flow index (MFI) 2.0 and melt strength of 32 cN, was kindly supplied Borealis, Germany. Actafoam (AZ -130 Galata Chemicals) was used as the chemical blowing agent for foaming LDPE. The nucleating agent in the foam layer was 1 wt\% Talc (Jetfine ${ }^{\circledR} 1 \mathrm{H}$, IMERYS Talc).

In order to produce the multilayered film/foam structures, a two-component microlayer coextrusion setup with multipliers was used. One extruder contained the foam layer polymer (LDPE), chemical blowing agent (Actafoam) and nucleating agent (Talc) and the other extruder contained the film layer polymer (LDPE or PP). After merging in the two-component feedblock, the foam and the film layers were formed into multilayers using the layer multipliers. Fig. 1 gives a general overview of the two-component coextrusion setup. Total pump rate in both extruder was varied to change the volumetric composition of film and foam layers in each sample. Table 2 shows the different formulations, layer numbers and systems which were produced by co-extrusion. A processing temperature of $190{ }^{\circ} \mathrm{C}$ was used for optimum foaming based on the decomposition kinetics of Actafoam AZ 130. A 3" exit die was used at the end of the multipliers. A chill roll setup was used as a sheet take-off.

\subsection{Thermal Analysis of LDPEs and foaming agent}

The melting point and crystallinity of each LDPE and PP samples were determined by using a differential scanning calorimeter (DSC) (Pyris1, PerkinElmer) in nitrogen atmosphere at a constant heating rate of $10{ }^{\circ} \mathrm{C} / \mathrm{min}$ in the temperature range -30 to $200{ }^{\circ} \mathrm{C}$. Melting point was determined from the peak value of endothermic peak in the second heating scan. The percent 
crystallinity of each LDPE sample was determined by using the melt enthalpy of fusion from DSC analysis.

The decomposition kinetics of the chemical blowing agent (Actafoam AZ 130) was investigated by thermogravimetric analyzer (TGA, TA Q500).

\subsection{Rheological Measurements}

The melt viscosity of different LDPE grades was determined using a Keyness Galaxy 1 melt flow indexer at a low shear rate, $10 \mathrm{sec}^{-1}$. This low shear rate was selected to simulate polymer flow conditions in the layer multiplication dies of the polymer melt streams during the layer multiplication process [35]. Fig. 2 shows the viscosities of different LDPE grades as a function of temperatures.

The shear flow properties were performed in a rotational rheometer (ARES-G2 from TA Instruments) equipped with parallel plates of $25 \mathrm{~mm}$ diameter. Sample thickness was $1 \mathrm{~mm}$. The frequency sweeps were performed at $190^{\circ} \mathrm{C}$ with the angular frequency ranged between 0.1 and $100 \mathrm{rad} / \mathrm{s}$.

The uniaxial extensional flow measurements were conducted on a Paar Physica MCR 501 from Anton Paar, coupled with the Sentmanat extensional fixture [36]. The temperature for the uniaxial extensional flow measurements was set at $130^{\circ} \mathrm{C}$ in order to avoid the sagging of the samples; all under different constant rates of deformation ranging from 0.1 to $10 \mathrm{~s}^{-1}$. Rectangular specimens of length $12.7 \mathrm{~mm}$, width $12.5 \mathrm{~mm}$, and thickness of $0.8 \mathrm{~mm}$ were molded at $190^{\circ} \mathrm{C}$ in a compression mold. The specimens were subjected to $190^{\circ} \mathrm{C}$ for 5 minutes during molding. Prior to testing, the rheometer was first heated and kept at a set temperature for 5 minutes to 
reach equilibrium. Sample preparation and loading followed the procedure recommended by Barroso et al. [37].

\subsection{Scanning Electron Microscopy of film/foam systems}

Scanning electron microscope (SEM) (JEOL) was used to observe the film/foam layered structures in each sample. Film/foam samples were cut in extrusion direction with sharp blades at room temperature and then sputter coated with gold $(8 \mathrm{~nm})$ for observation in SEM with an emission voltage of $30 \mathrm{kV}$.

The cell size and cell density of each film/foam samples were determined from SEM micrographs. The cell density $\left(\mathrm{N}_{0}\right)$ was determined using the following equation [38]:

$N_{o}=\left[\left[\frac{n M^{2}}{A}\right]^{3 / 2}\left[\frac{1}{1-V_{f}}\right]\right]$

Where $\mathrm{n}$ is the number of cells in SEM micrographs, $\mathrm{M}$ is the magnification factor, $\mathrm{A}$ is the area of micrograph $\left(\mathrm{cm}^{2}\right)$, and $V_{\mathrm{f}}$ is the void fraction of the foamed sample, which can be estimated as $V_{f}=\left[1-\frac{\rho_{f}}{\rho}\right]$

Where $\rho$ is the density of unfoamed materials and $\rho_{\mathrm{f}}$ is the density of foamed materials.

\subsection{Density Measurement of film/foam samples}

A liquid displacement method (ASTM D 3575-93, W-B) was used to measure the overall density of the foam/film samples.

\subsection{Mechanical Properties}


Tensile deformation behavior of each film/foam system was investigated on microtensile bars $(1.5 \times 4.7 \times 25) \mathrm{mm}^{3}$. Tensile tests were performed in a mechanical testing machine (MTS Alliance RT/30) with a strain rate of $100 \% / \mathrm{min}$ and the stress-strain curves were generated from the load-displacement curve obtained from the machine. All tests were performed at room temperature.

\section{Results and Discussion}

\subsection{Rheology of LDPE and Processing of multilayer LDPE/LDPE Film/Foam}

The coextrusion process for the production of film/foam layered systems is different in comparison with the production of multilayer polymer films. This is because one of the two extruders is used to mix the chemical blowing agent with the polymer melt. As described in Fig. 1, film polymer melt and foam polymer melt streams (polymer melt with decomposed chemical blowing agent) will merge in the feedblock and then flow through the multipliers. During the multiplication, the two polymer melt streams get doubled through a process of cutting, spreading and stacking the viscoelastic polymer melt [24]. A series of $n$ multiplying elements combines two polymers as $2^{(\mathrm{n}+1)}$ alternating layers as shown in Fig. 1.

As a whole, the film/foam coextrusion process involves three different stages: nucleation, cell growth and stabilization [34]. The nucleation of dissolved gas starts when film/foam layered sheets experience a pressure drop as it comes out of the exit die. The cells start to grow in the foam layer as more gas diffuses into them. At the end, cell growth stops when the temperature goes below the crystallization point of the polymer or as it reaches room temperature. The stabilization stage is largely dependent on the transition points of the foam polymer. This is why 
a lower temperature is usually used at the exit die to facilitate the stabilization of cell growth in foam layers.

In addition, the layer stability of film/foam sheets is significantly affected by the relative magnitudes of the cell growth stress and the melt strength of the film layer during coextrusion [34]. Thus, the right choice of film material and an optimum concentration of the blowing agent are essential to ensure that there is maximum foaming without layer break-up [34]. The right choice of film or foam materials refers to their viscoelastic behavior at melt, which is a function of their molecular structure. Both the shear and extensional viscosities of the film layer polymer should be high enough to resist the cell growth stress from the foam layer in order to maintain the layer integrity.

Fig. 2 shows the apparent viscosity profile of three different LDPEs as a function of temperature. The viscosity was measured in a melt flow indexer where the polymer melt flows through a capillary tube of specific diameter under a certain pressure for a certain period of time. It can be noticed that since each LDPE has different MFIs, the processing temperatures are also different. As expected, higher viscosity is observed with low MFI LDPEs (i.e. MFI 2 or MFI 4).

It is well-known that layer stability during coextrusion and multiplication is significantly affected by the melt elasticity of two polymers. Figure $3(\mathrm{a} \& \mathrm{~b}$ ) shows the complex viscosity as well as the melt elasticity of different LDPEs at $130{ }^{\circ} \mathrm{C}$ (the exit die temperature was kept at $130{ }^{\circ} \mathrm{C}$ ). It can be noticed that in addition to having different melt flow indices, LDPEs also exhibit different melt elasticity indexes. During the processing of film/foams, a melt elasticity ratio was also maintained between the film and foam layer LDPEs. 
LDPE contains long-chain branches with a tree-like branching architecture and this branching leads to a significant increase of the elongational viscosity $\left(\eta_{e},\right)$ which is essential for their good foaming behavior and thus most of the LDPEs exhibit good foaming in extrusion [39-41]. Foam expansion is an extensional-driven process and thus elongational viscosity $\left(\eta_{e}\right)$ plays an important role during the cell formation in foam layer when the melt flow comes out of the exit die. The extensional viscosity study was carried out at different strain rates. Fig. 4 (a, b \& c) shows the transient extensional viscosity of three different LDPEs at $130{ }^{\circ} \mathrm{C}$. Three different extensional rates were used $0.1,1.0$ and $10 \mathrm{~s}^{-1}$. The solid line represents the time-dependent steady shear viscosity of the samples. It can be noticed that all LDPE samples show strain hardening behavior at strain rates equal to $1 \mathrm{~s}^{-1}$ or above as the extensional viscosity increases above the linear viscoelasticity limit.

However, it can be noticed that at low strain rate (i.e. $0.1 \mathrm{~s}^{-1}$ ) LDPE MFI 2 shows higher strain hardening than MFI 4 and strain softening was observed only for MFI 8 samples. Since the foaming process upon extrusion is very fast, and given that the degrees of strain-hardening are very similar for all LPDEs at high strain rates, it is to be expect that all will show good foaming efficiency.

Based on the data obtained in the viscosity test, a viscosity contrast between film and foam layer has been maintained to develop film/foam systems (as reported in Table 2). This means LDPEs that show higher viscosity and melt elasticity at the processing temperature were used as the film layer polymer and lower viscosity ones in the foam layer. However, LDPEs with matched viscosity in both layers have also been produced to compare the layer integrity between viscosity 
matched and mismatched system. In addition, PP/LDPE film/foam systems have also been developed, where the PP film layer maintains higher viscosity than LDPE foam layer.

\subsection{Multilayer architecture of film/foam (LDPE/LDPE) systems}

The following discussion illuminates the effect of viscosity, foam content and layer number on the layered morphology of each film/foam system. It is important to mention here that all the samples studied here were taken from the center portion of samples due to the existence of melt flow circulation patterns close to or at the edge of the samples.

\subsubsection{Multilayer structures in viscosity matched film/foam systems}

Fig. 5 shows the SEM micrographs of the cross-section (in the extrusion direction) of film/foam samples that contain similar viscosity LDPEs in both film and foam layers (i.e. MFI 2 (film)/MFI 2 (foam) and MFI 4/MFI 4). Layered morphology is evident in each system at $50 \mathrm{v} \%$ foam content. Moreover, layered morphology can be achieved up to 16 layers in such film/foam systems. However, layered morphology was not evident when layer number exceeded 16 or the foam content was more than $50 \mathrm{v} \%$ in the system.

3.2.2. Effect of viscosity contrast between film and foam layers on the morphology of multilayer film/foam systems

Fig. 6 shows the effect of viscosity contrast between film and foam layer on 8 layer film/foam systems. Note that high viscosity LDPE was used as the film layer polymer and lower viscosity LDPE as the foam layer in each system. Interestingly, a layered morphology can be achieved 
even with $80 \mathrm{v} \%$ foam content for such film/foam systems, which means the high-viscosity film layers successfully confine the cell growth.

Layered morphologies are also evident in 16-layer film/foam systems at each foam content as can be seen in Fig. 7. It is noticeable that in each 16-layer system, arrays of single cells can be observed in the foam layers which was not observed in the viscosity matched film/foam systems (Fig. 5). Such evolution of architecture can be correlated to the suppressed cell growth as a function of increased layer number in the system [34]. Such morphology is a unique characteristic of the viscosity mismatched film/foam (16 L) systems.

Layered film/foam morphology was also observed in 32-layer film/foam systems (Fig. 8). A single cell layer can still be observed in each foam layers of film/foam system. Important to notice here that some randomness in cell size could be observed at the middle of the crosssection of 32 layer samples. However, no layered morphology can be observed if viscosity contrast between layers is not maintained.

Fig. 9 shows the SEM images of PP/LDPE (50/50) film/foam systems having 8, 16 and 32 layers. Layered morphology can be observed in PP/LDPE film/foam systems. Single cell array can also be observed in 16 and 32 layer samples. In addition, average cell size also decreased from $80 \mu \mathrm{m}(8 \mathrm{~L})$ to $35 \mu \mathrm{m}(32 \mathrm{~L})$. Another important aspect of multilayer film/foam structures is the anisotropic orientation of cells in foam layers. Barger et al. [19] showed that cells are more elongated in the flow direction or extrusion direction. Such anisotropic cell orientation is evident in all multilayer LDPE film/foams. 
It is evident from the above discussion that better layer integrity can be achieved by maintaining high viscosity contrast between film and foam layers. Fig. 10 demonstrates the fact that layer uniformity in each film/foam system can be improved as the viscosity ratio between film and foam layer increases. In addition, no layer break-up is observed when the film layer LDPE has higher viscosity than the foam layer LDPE. The high viscosity film layer acted as impermeable layers to the cell growth in the foam layers and thus resist the cell growth stress and confines the foam layer. This may have significant influence on the cell size distribution and cell density of each film/foam system which is discussed below.

\subsection{Confinement of Foam Layer}

Foam layers can be confined by increasing the number of layers, i.e., by decreasing the nominal thickness of each layer in the system [34]. Fig. 11 shows that the average cell size in foam layers can be reduced by decreasing the nominal layer thickness. In viscosity-mismatched systems, the cell size was reduced from $130 \mu \mathrm{m}$ to $80 \mu \mathrm{m}$ by increasing the layer number from 8 to 32 . This indicates that the foam layers get confined as we decrease the thickness of each layer by increasing the layer number. Such confinement effect was maintained even with higher foam content due to the high viscosity LDPEs in film layers. In addition, the cell density also increased significantly with increasing layer numbers and all such increases in cell density exhibited a corresponding reduction in the cell size of each system. This implies that the reduction in cell size can be attributed to the enhanced nucleation or suppressed cell coalescence under confinement. Such suppression of cell growth might have occurred at 16 layers, if there is a viscosity contrast between film and foam layers, where a single cell layer can be observed. Fig. 
12 demonstrates such an effect of viscosity contrast and layer number on the confinement of foam layer in each film/foam system. The presence of the single cell layer is more evident in the 16 layer samples having viscosity contrast between layers. This further proves the fact that high viscosity film layer is confining the foam layer. It is important to mention here that such confinement effect of foam layer can still be observed in 16 layer samples even with high foam content.

\subsection{Density of multilayer film/foam systems}

The bulk apparent density of each film/foam system is governed by their cell density and cell size. The density data is presented in Table 4 and it can be observed that the bulk density of each system decreases as the foam content increases. This decrease in bulk density is also a function of cell size increase due to the increase in foam content of each system [42]. Increase in layer number did not affect the density significantly. The density of all film/foam systems ranges from 0.55 to $0.33 \mathrm{~g} / \mathrm{cm}^{3}$.

\subsection{Tensile properties of film/foam systems}

Fig. 13 shows the stress-strain behavior of both solid (a) and foamed (b) LDPEs. Solid LDPE films show very high strain of deformation (Fig. 13 a) while the foamed LDPEs (foam controls) of same grades show reduced deformability (Fig. $13 \mathrm{~b}$ ). This is due to the reduced density of LDPEs. Foamed LDPEs show gradual yielding while the solid LDPEs show yielding at 12 to 15\% strain and strain hardening behavior at higher strain. Observe that LDPE MFI 8 shows lower yield stress (than MFI 2, MFI 4) but higher strain at break. 
Fig. 14 (a-e) shows the stress-strain behavior of different film/foam systems (with 50 v\% content) as a function of layer number. Fig. 14 (a \& b) show the stress-strain behavior of viscosity matched film/foam systems (i.e. MFI 2/MFI 2 and MFI 4/MFI 4). In both systems, the yield stress and elastic modulus increases as the layer number increases. However, observe that yield stress and modulus decrease at 32 layers. This is due to the layer break up in 32-layer viscosity-matched film/foam systems as is shown in Fig. 4. This indicates the importance of layer integrity for better mechanical performance of film/foam systems.

Fig. $14 \mathrm{c}, \mathrm{d}$ and e show the stress-strain behavior of film/foam systems with viscosity contrast between film and foam layers. It is evident that as the layer number increases both the tensile modulus and yield strength increases in each system. Such improvement in mechanical behavior can be attributed to the confinement effect of film layers on the cell size distribution and cell density of each system. Table 3 shows the increase in tensile modulus as a function of layer number increase in film/foam systems. In addition, fracture strain of each viscosity mismatched systems is higher than that of the viscosity matched system. Note that film/foam systems with 32 layers show the highest tensile modulus as well as maximum strain at break. All film/foam systems exhibited high fracture strain. Such improvement in deformability can be attributed to the layer uniformity in viscosity mismatched systems as explained in Fig. 10. Fig. 15 shows the stress-strain behavior PP/LDPE film/foam system. The strength and modulus increases with the layer number. However, fracture strain decreased for 32 layer samples.

Fig. 16 presents a general schematic for the deformation mechanism of LDPE/LDPE film/foam systems during the uniaxial tension. Three important points were selected on the stress-strain 
plot; at yield strain (15\% strain), at the cold drawing region (at $60 \%$ strain) and at the strain hardening region (at $130 \%$ strain). Samples were collected at each strain (\%) point and immediately transferred to the dry ice box in order to avoid any relaxation of stress. SEM microscopic analysis was carried out on cryo-tomed samples. Fig. 16 (a-d) shows the SEM images of deformed samples at each strain level.

Usually in the initial low strain region cell edges bend in the foam layer and stretching of cell faces take place with the increasing load [43]. Cell bending dominates in foam layers at the yield strain (15\% strain) (Fig. 16a). Further increase in load causes the stretching of cell walls in the loading direction. Stretching of cells at $60 \%$ strain can be observed in SEM images of deformed samples (Fig. 16b). At higher strain (130\% strain), in the region of strain hardening, cells get more elongated and densified. This is also known as the densification strain; the densification of cell walls leads to cell collapse and then cell edges start to break up and eventually develop cracks in each layer and the rupture takes place in film/foam systems.

On the other hand, Fig. 17 shows that fracture strain in viscosity matched systems (32 layers, no layer uniformity) is significantly influenced by the random distribution of cells. Fig. 17a shows that fracture propagates from the cell edges, which is also evident in the fracture surface of the sample (Fig. 17b).

It is evident in Fig. 16 and 17 that the deformation of the film/foam structures is mainly stretchdominated in tensile mode. Here, the stretch domination means that the cells in the foam layer will carry the tension that will fail before the film layer. It is important to mention that both the 
modulus and initial collapse strength of a stretch dominated cellular plastic are much greater than those of a bending-dominated (in compression mode) cellular material of the same relative density. This makes stretch-dominated cellular solids the best choice for lightweight structural applications [43].

It is clear from the above discussion that the deformation behavior of film/foam systems is significantly influenced by layer uniformity. In addition, the fracture strain, elastic modulus and tensile strength are also influenced by the layer integrity and foam content. Table 4 reports the effect of layer number on the tensile modulus and fracture strain of different film/foam systems. It can be observed that as the layer number increases both the tensile modulus and fracture strain increase in the viscosity-mismatched samples. On the other hand, in viscosity-matched samples, increases in tensile modulus and fracture strain could not be observed for 32-layer samples due to the layer break as evident in Fig. 5. It is important to notice that higher viscosity contrast samples (MFI 2/MFI 8) showed higher fracture strain than the other samples which is due to better layer integrity in that system.

\section{Conclusions}

Multilayer flexible film/foam systems with high foam content were successfully developed using multilayer coextrusion technology. In order to obtain film/foam systems with good layer integrity, a viscosity contrast between film and foam layer was maintained. It was found that good layer uniformity can be achieved when a viscosity contrast between film and foam layers is maintained even with high foam content. Higher foam content decreased the bulk density of the film/foam system while maintaining good layer uniformity. However, such layer uniformity cannot be observed without viscosity contrast between film and foam layers. In addition, the high 
viscosity film layers acted as the confining layer and thus single cell alignment can be observed in foam layers of viscosity mismatched systems.

Layer integrity also plays significant role in improving the mechanical performance of film/foam systems. Thus, higher fracture strain and higher modulus were observed for viscosity mismatched systems. It was also observed that by choosing the right pair of polymers while still maintaining the viscosity contrast between layers, as observed in PP/LDPE systems, mechanical properties can be tuned.

\section{Acknowledgements}

The authors are grateful to the National Science Foundation for financial support from the Science and Technology Center for Layered Polymer Systems under grant number 0423914.

\section{References:}

1. Eaves, D. Polyolefin Foams. In: Handbook of Polymer Foams. Rapra Technology Limited. UK 2004.

2. Zhang, Y., Rodrigue, D., \& Ait-Kadi, A. J Appl Polym Sci 2003; 90: 2111-2119.

3. Dounis, D. V., \& Wilkes, G. L. Polymer, 1997; 38: 2819-2828. Dounis, D. V., \& Wilkes, G. L. Polymer 1997; 38: 2819-2828.

4. Rodríguez-Pérez, M. A., Velasco, J. I., Arencon, D., Almanza, O., \& De Saja, J. A. J Appl Polym Sci 2000; 75(1):156-166.

5. Blyler, L. L., \& Kwei, T. K. J Polym Sci Part C: Polym Symp 1971; 35:165-176.

6. Kraynik, A. M. Polym Eng \& Sci, 1981; 21: 80-85.

7. Han, C. D., \& Villamizar, C. A. Polym Eng \& Sci, 1978;18: 687-698. 
8. Han, C. D. and Villamizar, C. A. J Appl Polym. Sci 1978; 22: 1677-1700.

9. Throne, J. L. In Engineering Guide to Structural Foams; Wendle, B. C., Technomic: Westport, CT, 1976.

10. Feldman, D. J Polym Sci C Polym Lett 1986; 24: 657.

11. Yamaguchi, M., \& Suzuki, K. I. J Polym Sci Part B: Polym Phys, 2001; 39:2159-2167.

12. Yang Y, Gupta MC, Dudley KL and Lawrence RW, Nano Lett 2005; 5: 2131-2134.

13. Thomassin, J. M., Pagnoulle, C., Bednarz, L., Huynen, I., Jerome, R., \& Detrembleur, C. J Mat Chem 2008; 18: 792-796.

14. Yang Y, Gupta MC, Dudley KL and Lawrence RW, Adv Mater 2007; 17: 1999-2003.

15. Li, Qingxiu, and Laurent M. Matuana. J App Polym Sci 2003; 88: 3139-3150.

16. Zheng, X. T., Wu, D. M., Meng, Q. Y., Wang, K. J., Liu, Y., Wan, L., \& Ren, D. Y. J Polym Res 2008;15: 59-65.

17. Boccaccio, A., Casavola, C., Lamberti, L., \& Pappalettere, C. Materials 2013; 6: 45454564.

18. Casavola, C., Moramarco, V., \& Pappalettere, C. Fatigue \& Fracture of Engineering Materials \& Structures, 2014; 37: 1377-1385.

19. Barger, M. A., Bland, D., Mazor, M. H., Baer, E., Dooley, J., \& Garcia, J. A. (2011). U.S. Patent Application 13/178,869.

20. Chisholm, D., \& Schrenk, W. J. (1971). U.S. Patent No. 3,557,265. Washington, DC: U.S. Patent and Trademark Office.

21. Dukess, J. (1980). U.S. Patent No. 4,206,165. Washington, DC: U.S. Patent and Trademark Office. 
22. Kelch, R. H. (1991). U.S. Patent No. 5,000,992. Washington, DC: U.S. Patent and Trademark Office.

23. Schulz, T. G., Danner, M. C., Cahill, G. J., \& Tung, H. C. (2000). U.S. Patent No. 6,164,739. Washington, DC: U.S. Patent and Trademark Office.

24. Ponting, M., Hiltner, A., \& Baer, E. Macromolecular symposia 2010; 294: 19-32.

25. J. Im, E. Baer, A. Hiltner, in: "High Performance Polymers', E. Baer, A. Moet, Eds., Hanser Publishers, New York 1991, p. 175.

26. E. Baer, J. Kerns, A. Hiltner, in: Cunha, António M., and Stoyko Fakirov, eds. Structure development during polymer processing. Vol. 370. Springer, 2000.

27. Ponting, M., Burt, T. M., Korley, L. T., Andrews, J., Hiltner, A., \& Baer, E. Ind \& Eng Chem Res 2010; 49: 12111-12118.

28. Lin, Y., Hiltner, A., \& Baer, E. Polymer, 2010; 51: 4218-4224.

29. Carr, J. M., Langhe, D. S., Ponting, M. T., Hiltner, A., \& Baer, E. J Mat Res, 2012; 27: 1326-1350.

30. Du, J., Armstrong, S. R., \& Baer, E. Polymer 2013; 54: 5399-5407.

31. Wang, J., Langhe, D., Ponting, M., Wnek, G. E., Korley, L. T., \& Baer, E. Polymer 2014; 55, 673-685.

32. Ji, S., Ponting, M., Lepkowicz, R. S., Rosenberg, A., Flynn, R., Beadie, G., \& Baer, E. Optics express 2012; 20: 26746-26754.

33. Armstrong, S. R., Offord, G. T., Paul, D. R., Freeman, B. D., Hiltner, A., \& Baer, E. J App Polym Sci 2014; 2: 131.

34. Ranade, A. P., Hiltner, A., Baer, E., \& Bland, D. G. J Cell Plast, 2004; 40: 497-507. 
35. Ponting, M., Lin, Y., Keum, J. K., Hiltner, A., \& Baer, E. Macromolecules 2010; 43: 8619-8627.

36. Sentmanat, M., \& Hatzikiriakos, S. G. Rheol. Acta 43, no. 6 (2004): 624-633.

37. Barroso, V. C., Covas, J. A., and Maia, J. M. Rheol. Acta 2002; 41: 154-161.

38. Muenstedt, H., Kurzbeck, S., \& Stange, J. Polym Eng \& Sci 2006; 46, 1190-1195.

39. Stadler, F. J., Kaschta, J., Münstedt, H., Becker, F., \& Buback, M. Rheologica acta 2009; 48: 479-490.

40. Dealy, J. M., \& Larson, R. G. Structure and rheology of molten polymers. Hanser, Munich, 2006.

41. Gibson, L. and Ashby, J. (1997). Cellular Solids: Structure and Properties, Chapters 6 and 12, Cambridge University Press, Cambridge, CB2 2RU, UK.

42. Ramesh, N. S. "Foam growth in polymers." Lee, Shau-Tarng, ed. Foam extrusion: principles and practice. CRC press, 2002.

43. Ashby, M. F. Philosophical Transactions of the Royal Society A: Mathematical, Physical and Engineering Sciences 2006; 364: 15-30.

44. Mathot, Vincent BF, ed. Calorimetry and Thermal Analysis of Polymers. Munich, Hanser, 1991.

\section{Table Captions:}

Table 1. Properties of different polymers used for co-extrusion.

Table 2: Overview of different LDPE/LDPE film/foam systems produced in this research work.

Table 3. Effect of foam content and layer number on the density of film/foam.

Table 4: Effect of layer number on the tensile modulus of different film/foam (50/50) samples. 


\section{Figure Captions:}

Fig. 1. A generalized diagram showing the two-component setup for the co-extrusion of multilayer film/foam systems. Diagram in the lower left is showing the horizontal multiplication of film and foam layer polymers. Formation of film/foam layers at the exit die is also shown on the lower right diagram.

Fig. 2: Apparent Viscosity profile of different LDPEs and PP as a function of the processing temperature. The plots show the difference in viscosities at the processing temperature between film and foam layer LDPEs.

Fig. 3. Complex viscosity (a) and storage modulus (b) of different LDPEs as the function of their melt flow indices at $130{ }^{\circ} \mathrm{C}$.

Fig. 4. Transient Trouton ratio of different LDPEs as the function of Hencky strain at different extensional rates $\left(\mathrm{s}^{-1}\right)$. Trouton ration is used to quantify the deviation from linear viscoelastic behavior at a given level of strain. Note that strain hardening is very prominent and almost equal for all LDPEs at higher extensional rates.

Fig. 5. SEM images showing cross-sections (in extrusion direction) of 8, 16 and 32 layers film/foam (50/50) systems having similar viscosity LDPE in film and foam layers. Samples with more than $50 \mathrm{v} \%$ foam content could not be obtained with good layer integrity. Layer break up can be observed in 32 layer film/foam systems.

Fig. 6. SEM images showing the effect of foam content (50 and $70 \mathrm{v} \%)$ and viscosity contrast between film and foam layers on the layer integrity in 8 layer film/foam systems. Improved layer integrity can be observed in all film/foam systems. 
Fig. 7. SEM images showing the effect of foam content (50,70 and $80 \mathrm{v} \%$ ) and viscosity contrast between film and foam layers of 16 layers film/foam systems. Layered morphology is evident in each system.

Fig. 8. SEM images showing the effect of viscosity contrast between film and foam layers on 32 layers film/foam (50/50) structures.

Fig. 9. Optical images showing the film/foam layered morphology of PP/LDPE systems having 8 (a), 16 (b) and 32 (c) layers.

Fig. 10: Layer uniformity in different film/foam systems having viscosity contrast between film and foam layer LDPEs. This plot shows layer uniformity as a function of viscosity ratio and layer number in different film/foam (50/50) systems. Layer uniformity improves as the viscosity ratio increases between film and foam layers.

Fig. 11. Effect of layer thickness on the average cell size and cell density of film/foam (50/50) samples. This graph explains the confinement effect due to increasing the number of film layers that influences the cell density and cell size significantly.

Fig. 12. Effect of viscosity contrast and layer number on the confinement of cells between film layers in each film/foam system. This graph shows that as the number of film layers increases, especially in viscosity contrast samples, the ratio between the height of cells and thickness of foam layers containing the cells, moves toward unity indicating the single cell alignment in foam layers.

Fig. 13. Stress-strain behavior of LDPE films control (a) and foam controls (b). Note that in each film/foam systems LDPE with MFI 2 and MFI 4 have been used as the film layer polymers while MFI 2, MFI 4 and MFI 8 have been used as the foam layer polymers. It can be noticed that foaming of solid polymer led to the decrease in both strength and deformability of samples. 
Fig. 14. Effect of layer number on the stress-strain behavior of LDPE/LDPE film/foam systems; (a) MFI 4/MFI 4, (b) MFI 2/MFI 2, (c) MFI 2/MFI 4, (d) MFI 2/MFI 8 and (e) MFI 4/MFI 8 film/foam systems.

Fig. 15: Effect of layer number on the stress-strain behavior of PP/LDPE (50/50) Film/Foam systems.

Fig. 16. Deformation mechanism of uniformly layered film/foam system. The SEM images showing the structural response to each level of deformation. Note that $16 \mathrm{~L}$ film/foam (MFI 2/MFI 4) sample was studied here.

Fig. 17. SEM images showing the structural changes during tensile deformation in film/foam samples with no layer integrity (MFI 2/MFI 2, 32 L).

Table 1. Properties of different polymers used for co-extrusion.

\begin{tabular}{|c|c|c|c|c|c|}
\hline Trade Names & $\begin{array}{l}\text { Density } \\
\left(\mathrm{g} / \mathrm{cm}^{3}\right)\end{array}$ & $\begin{array}{c}\text { Melt flow Index }{ }^{a} \\
\left(190{ }^{\circ} \mathrm{C} / 2.16 \mathrm{~kg}\right) \\
(\mathrm{g} / 10 \mathrm{~min})\end{array}$ & $\begin{array}{c}\text { Crystallization } \\
\text { Temperature } \\
\left({ }^{0} \mathrm{C}\right)\end{array}$ & Crystallinity $^{b}$ & $\begin{array}{c}\text { Melting } \\
\text { point } \\
\left({ }^{0} \mathrm{C}\right)\end{array}$ \\
\hline LDPE 5011 & 0.922 & 1.9 & 93 & 39 & 109 \\
\hline LDPE 50041 & 0.924 & 4.2 & 97 & 33 & 110 \\
\hline LDPE 722 & 0.918 & 8.0 & 91 & 35 & 105 \\
\hline
\end{tabular}


${ }_{b}^{a}$ data were provided by the manufacturer

crystallinity was determined by using the melt enthalpy of fusion obtained from DSC analysis of samples. The heat of fusion for $100 \%$ crystalline LDPE is $293 \mathrm{~J} / \mathrm{g}$ [44].

Table 2: Overview of different film/foam systems produced in this research work.

\begin{tabular}{|c|c|c|c|}
\hline $\begin{array}{c}\text { Film/Foam Systems } \\
\text { (LDPE/LDPE) }\end{array}$ & $\begin{array}{c}\text { Designation } \\
\text { Names }\end{array}$ & $\begin{array}{c}\text { Foam Content } \\
(\mathrm{V} \%)\end{array}$ & Number of layers \\
\hline LDPE 5011/ LDPE 5011 & MFI 2/MFI 2 & 50 & \\
\hline LDPE 5041/ LDPE 5041 & MFI 4/MFI 4 & 50 & \\
\hline
\end{tabular}


LDPE 5011/ LDPE 5041

LDPE 5011/ LDPE 722

LDPE 5041/ LDPE 722

PP WB140 HMS/LDPE 5011
MFI 2/MFI 4

MFI 2/MFI 8

MFI 4/ MFI 8

PP/LDPE
$50,70,80$

$50,70,80$

$50,70,80$

50

Table 3. Effect of foam content and layer number on the density of LDPE/LDPE film/foams.

\begin{tabular}{lcccccc}
\hline $\begin{array}{l}\text { Layer } \\
\text { Number }\end{array}$ & $\begin{array}{c}\text { Foam } \\
\text { Content } \\
(\mathbf{v} \%)\end{array}$ & MFI 2/MFI 2 & MFI 4/MFI 4 & MFI 2/MFI 4 & MFI 2/MFI 8 & MFI 4/MFI 8 \\
\cline { 3 - 7 } & 50 & 0.41 & 0.42 & 0.48 & 0.44 & 0.38 \\
8 Layers & 70 & $0.40^{*}$ & $0.40^{*}$ & 0.40 & 0.38 & 0.33
\end{tabular}




\begin{tabular}{cccccc}
80 & $0.38^{*}$ & $0.37^{*}$ & 0.33 & 0.32 & $0.30^{*}$ \\
\hline 50 & 0.55 & 0.49 & 0.48 & 0.45 & 0.46
\end{tabular}

\begin{tabular}{lcccccc} 
16 Layers & 70 & $0.48^{*}$ & $0.46^{*}$ & 0.42 & 0.39 & 0.40 \\
& & & & & & 0.38 \\
& & $0.40^{*}$ & $0.41^{*}$ & 0.39 & 0.35 & 0.38 \\
\cline { 2 - 7 } 32 Layers & 50 & 0.49 & 0.48 & 0.46 & 0.45 & 0.45
\end{tabular}

* Layer integrity was not observed in these samples (having no viscosity contrast between layers).

Table 4: Effect of layer number on the tensile modulus of different film/foam (50/50) samples.

\begin{tabular}{|c|c|c|}
\hline Film/Foam Systems & Young's Modulus (MPa) & Fracture Strain (\%) \\
\hline (LDPE/LDPE) & 32 Layers & 16 Layers \\
\hline
\end{tabular}




\begin{tabular}{lcccccc}
\hline MFI 2/ MFI 2 & $102 \pm 8$ & $119 \pm 9$ & $67 \pm 7$ & $80 \pm 12$ & $108 \pm 14$ & $80 \pm 10$ \\
MFI 4/ MFI 4 & $88 \pm 5$ & $103 \pm 8$ & $93 \pm 9$ & $65 \pm 8$ & $125 \pm 18$ & $118 \pm 13$ \\
MFI 2/ MFI 4 & $66 \pm 7$ & $83 \pm 8$ & $129 \pm 8$ & $118 \pm 11$ & $121 \pm 13$ & $125 \pm 14$ \\
MFI 2/ MFI 8 & $71 \pm 4$ & $76 \pm 6$ & $111 \pm 8$ & $125 \pm 14$ & $143 \pm 12$ & $171 \pm 15$ \\
MFI 4 / MFI 8 & $72 \pm 5$ & $102 \pm 4$ & $110 \pm 6$ & $101 \pm 10$ & $110 \pm 13$ & $128 \pm 17$ \\
PP/LDPE & $184 \pm 2$ & $260 \pm 10$ & $350 \pm 15$ & $80 \pm 30$ & $65 \pm 5$ & $36 \pm 4$ \\
\hline
\end{tabular}




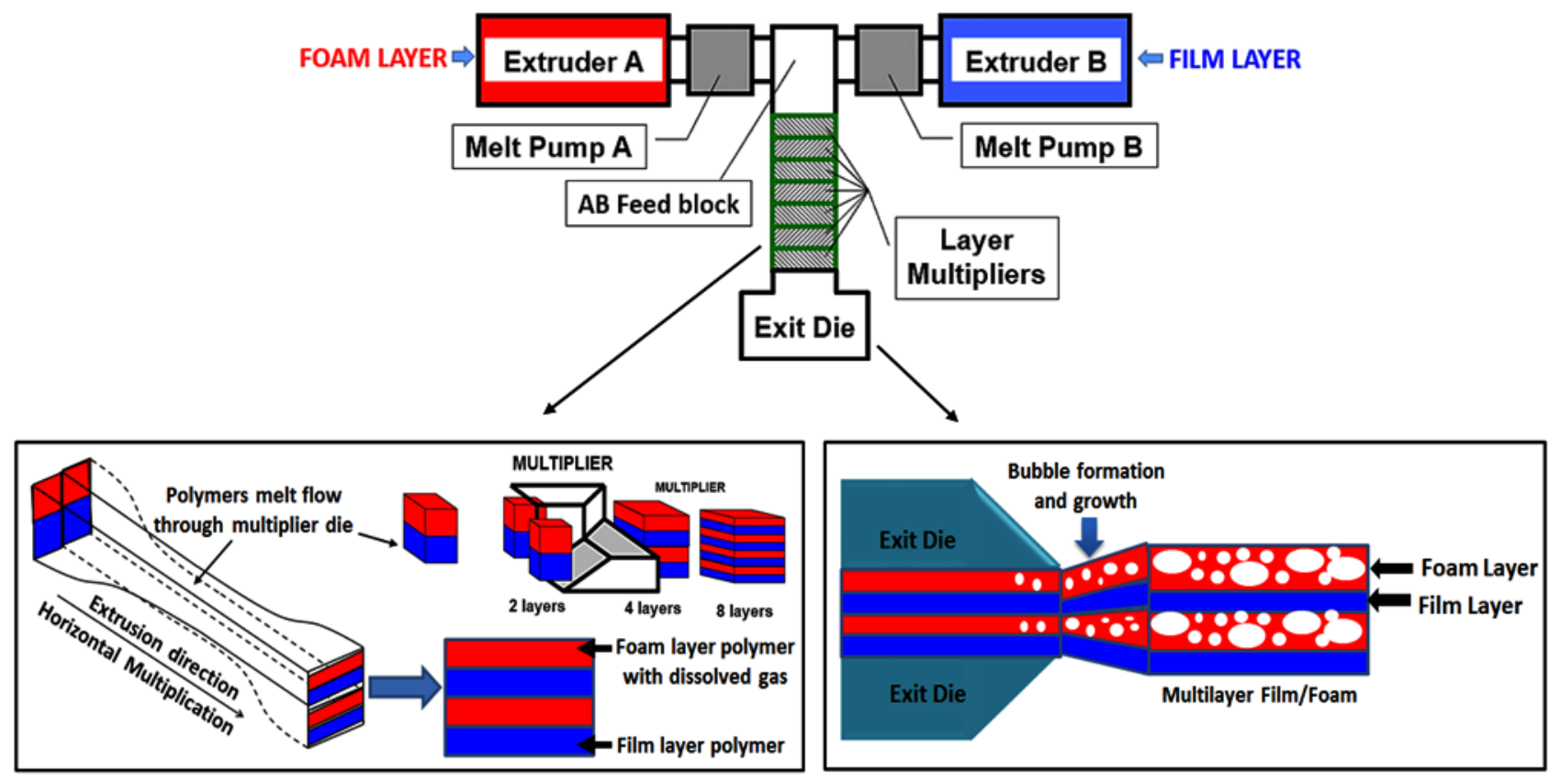

Fig. 1. A generalized diagram showing the two-component setup for the co-extrusion of multilayer film/foam systems. Diagram in the lower left is showing the horizontal multiplication of film and foam layer polymers. Formation of film/foam layers at the exit die is also shown on the lower right diagram. 


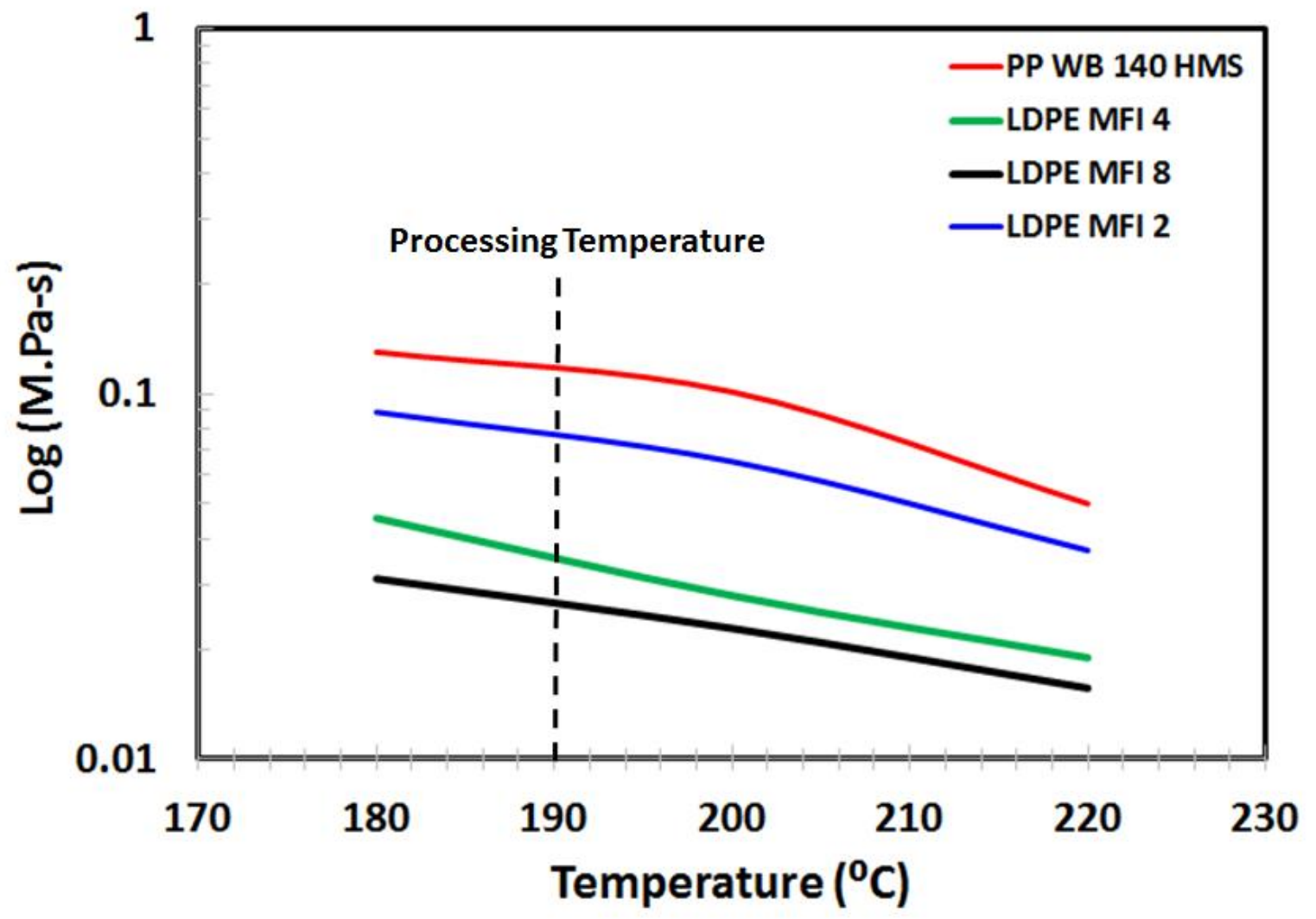

Fig. 2: Apparent Viscosity profile of different LDPEs and PP as a function of the processing temperature. The plot shows the difference in viscosities at the processing temperature between film and foam layer LDPEs. 

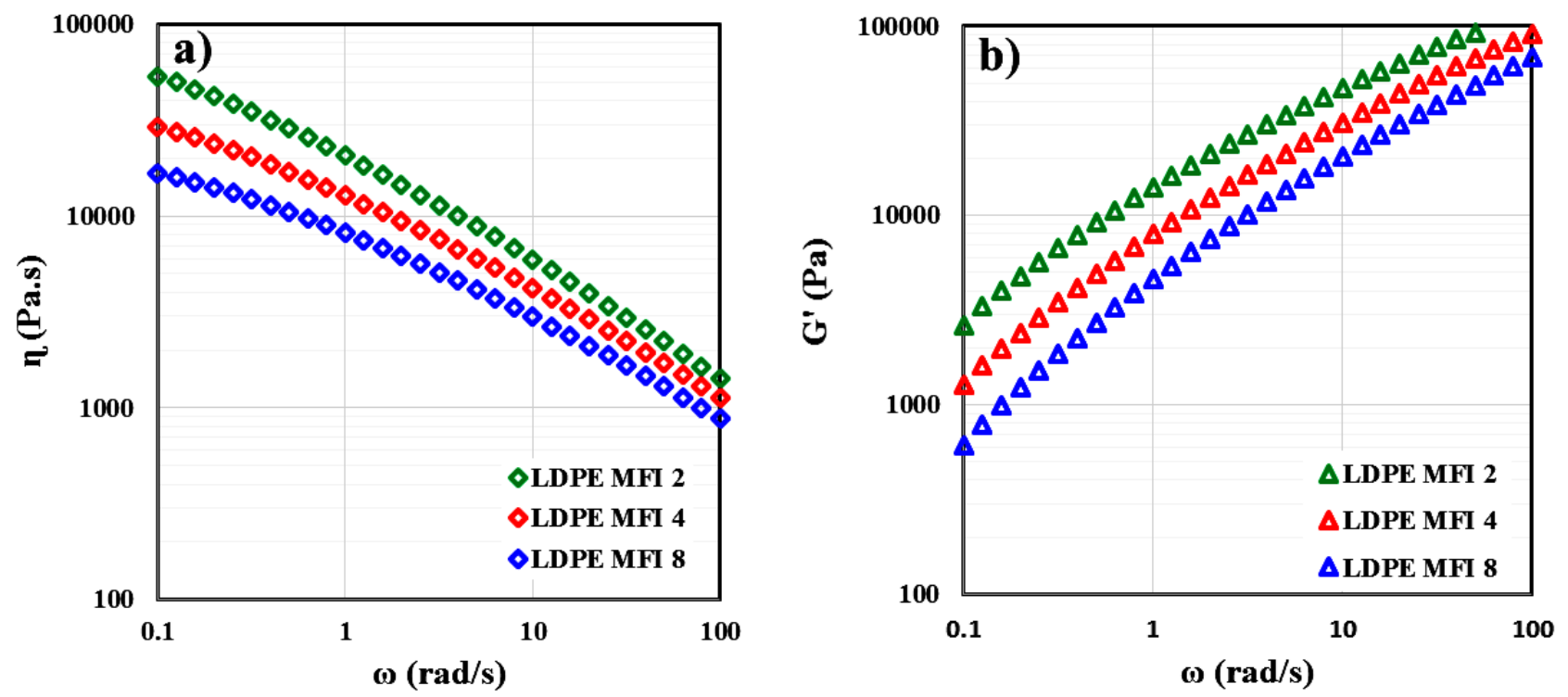

Fig. 3. Complex viscosity (a) and storage modulus (b) of different LDPEs as the function of their melt flow indices at $130{ }^{\circ} \mathrm{C}$. 

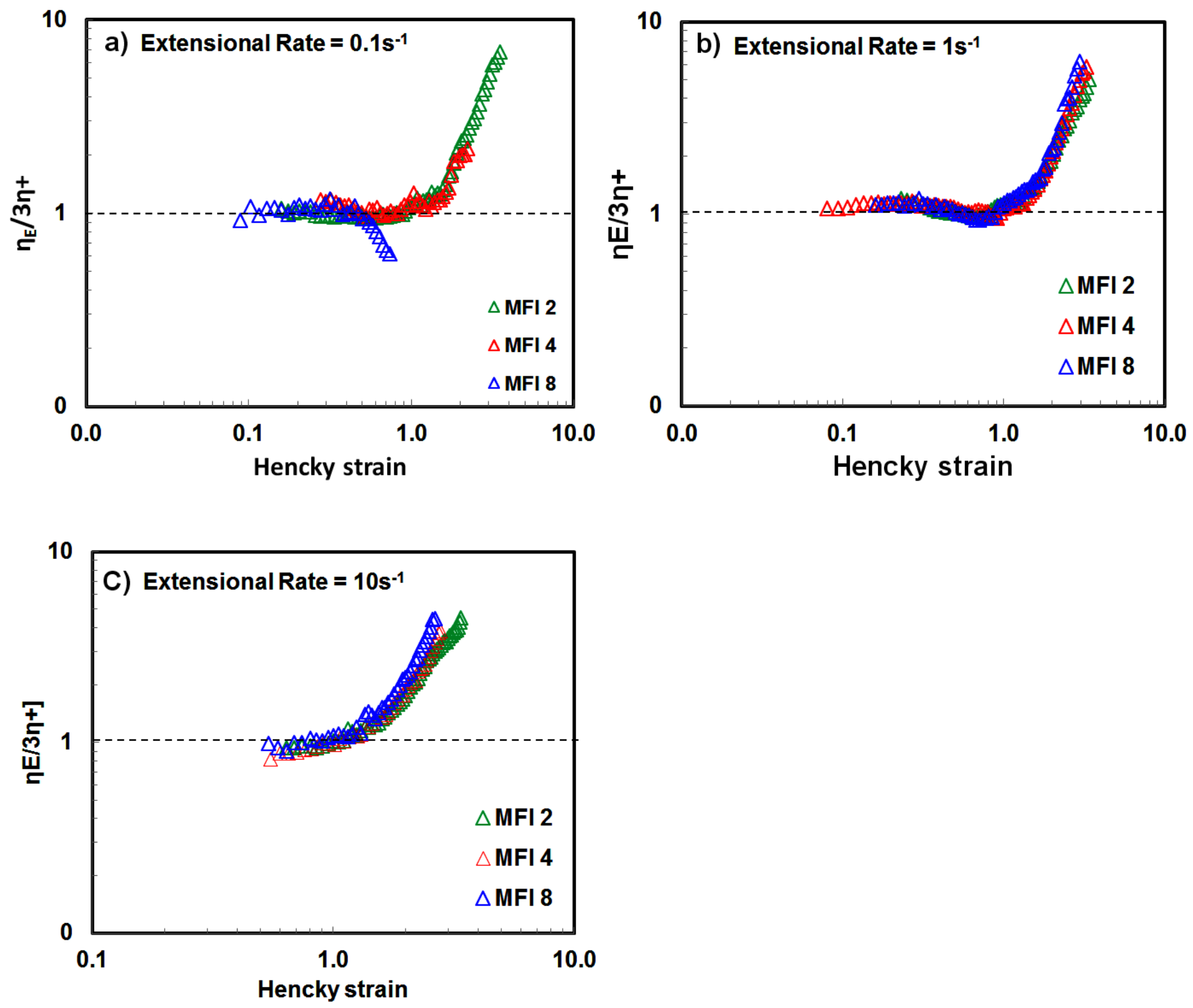

Fig. 4. Transient Trouton ratio of different LDPEs as the function of Hencky strain at different extensional rates $\left(\mathrm{s}^{-1}\right)$. Trouton ration is used to quantify the deviation from linear viscoelastic behavior at a given level of strain. Note that strain hardening is very prominent and almost equal for all LDPEs at higher extensional rates. 


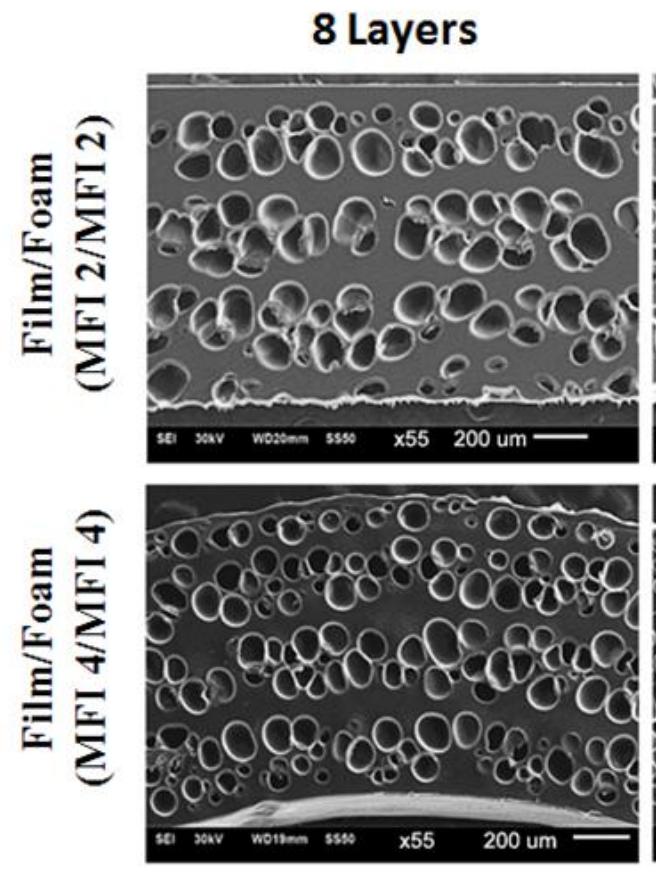

16 Layers
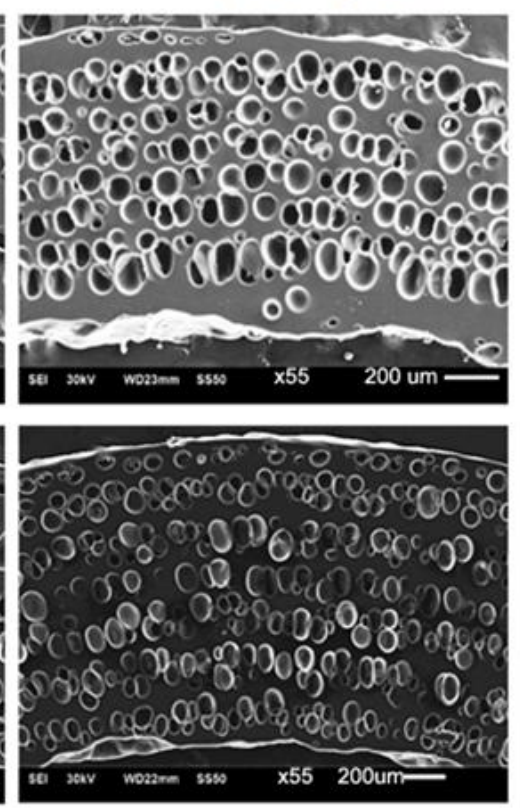

32 Layers
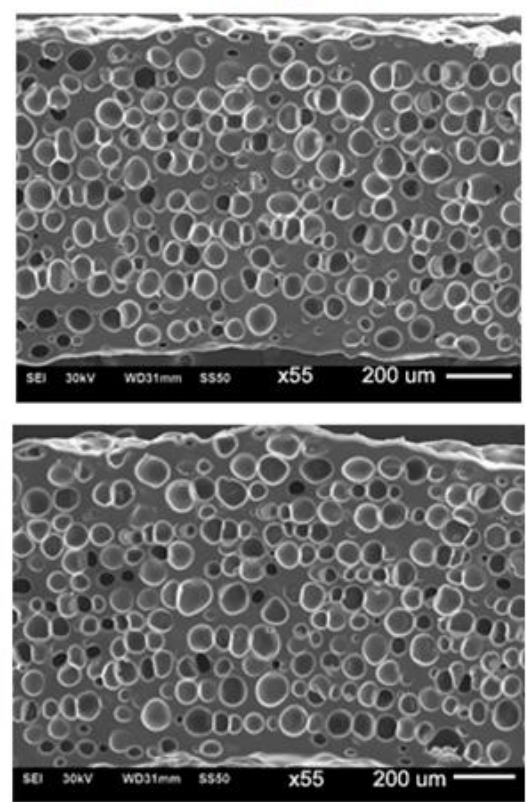

Fig. 5. SEM images showing cross-sections (in extrusion direction) of 8,16 and 32 layers film/foam (50/50) systems having similar viscosity LDPE in film and foam layers. Samples with more than $50 \mathrm{v} \%$ foam content could not be obtained with good layer integrity. In addition, layer break up can be observed in 32 layer film/foam systems. 

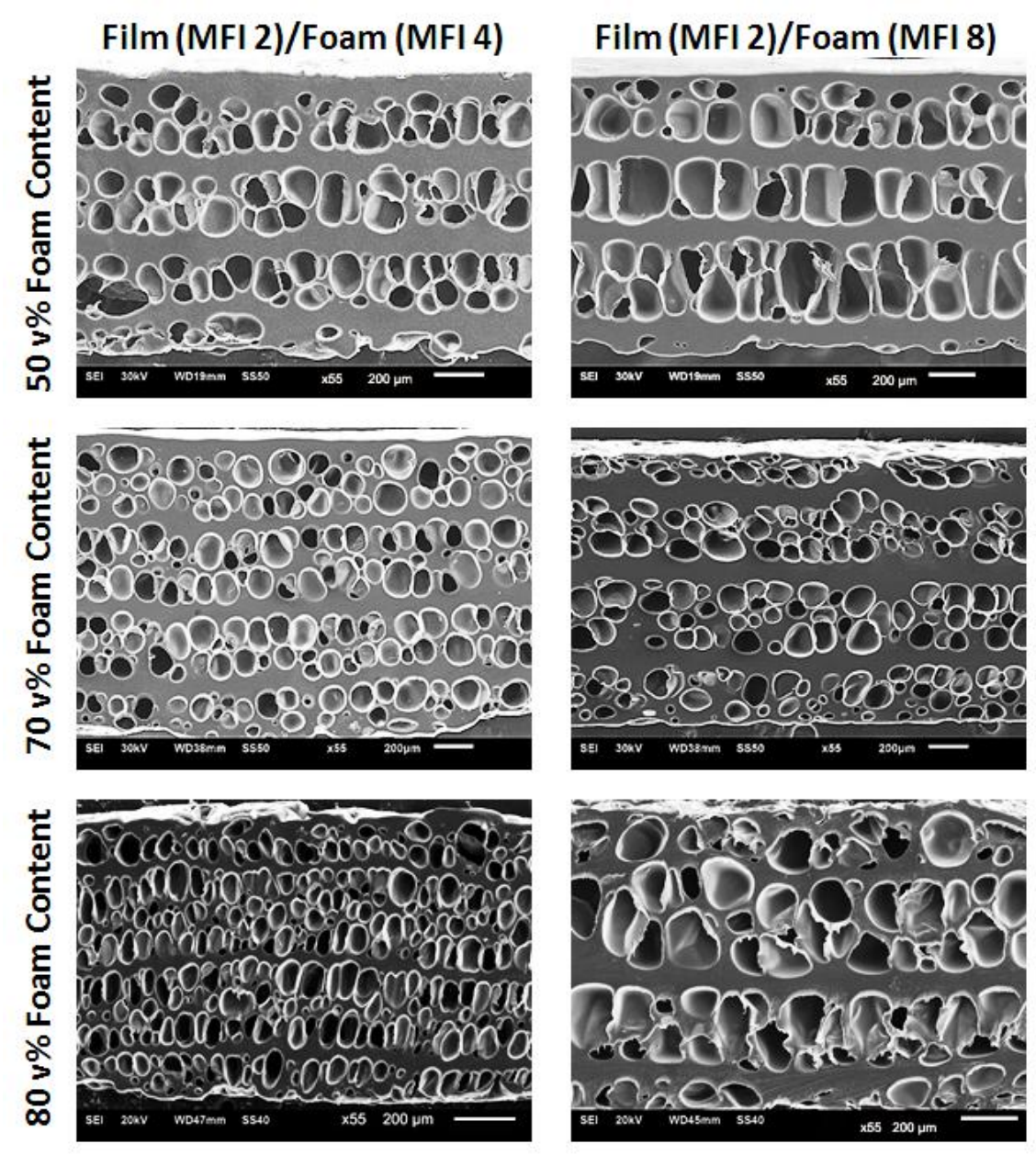

Film (MFI 4)/Foam (MFI 8)
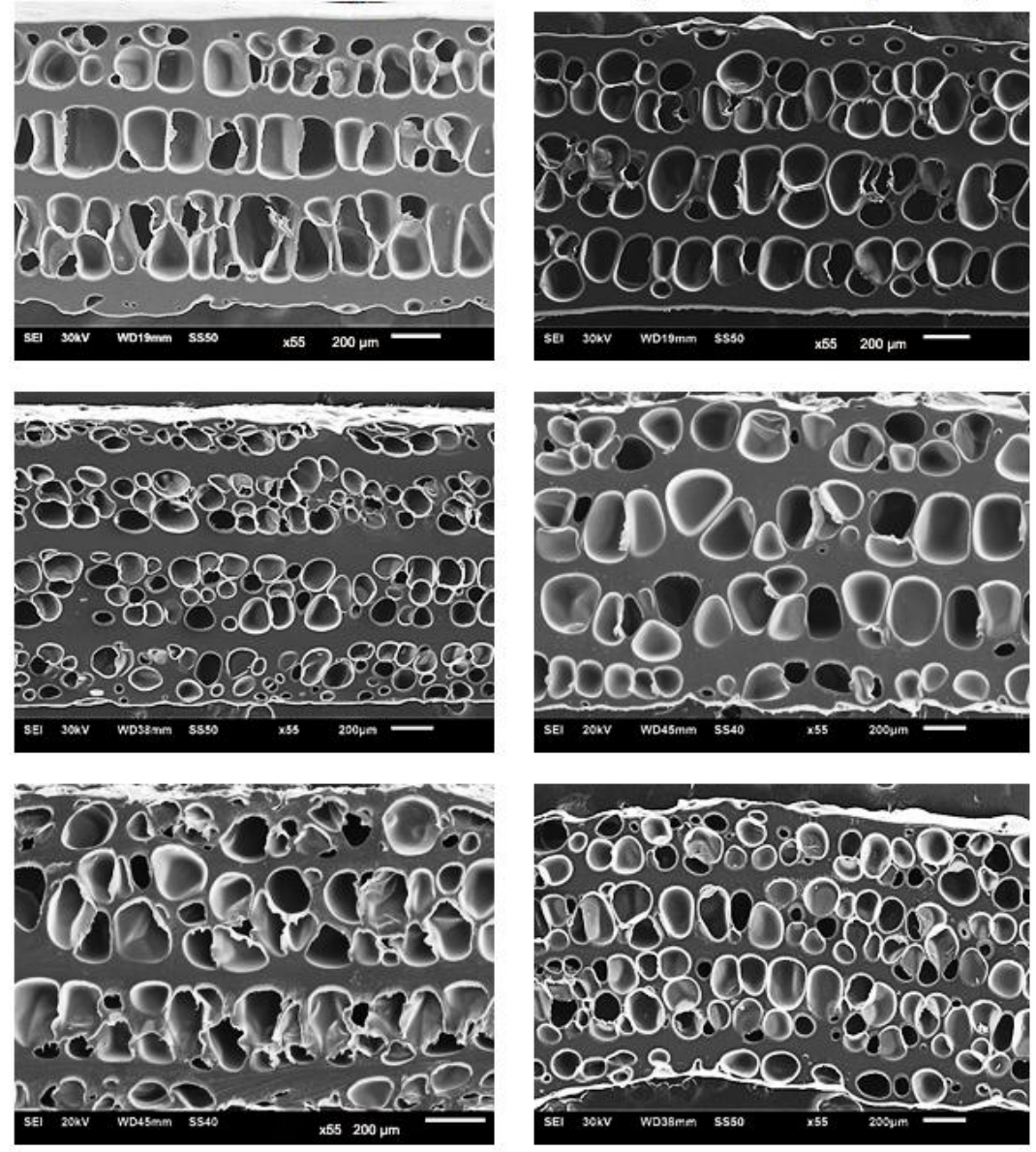

Fig. 6. SEM images showing the effect of foam content (50,70 and $80 \mathrm{v} \%$ ) and viscosity contrast between film and foam layers on the layer integrity in 8 layer film/foam systems. Improved layer integrity can be observed in all film/foam systems. 
Film (MFI 2)/Foam (MFI4)

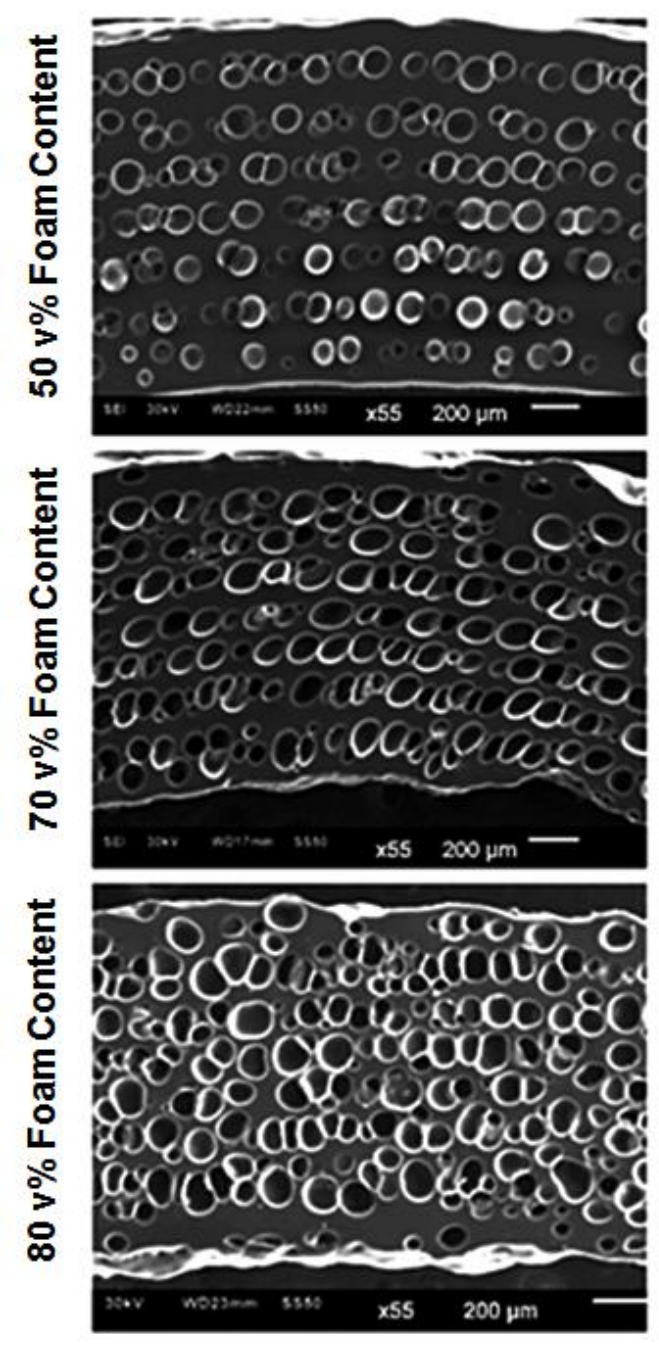

Film (MFI 2)/Foam (MFI 8)
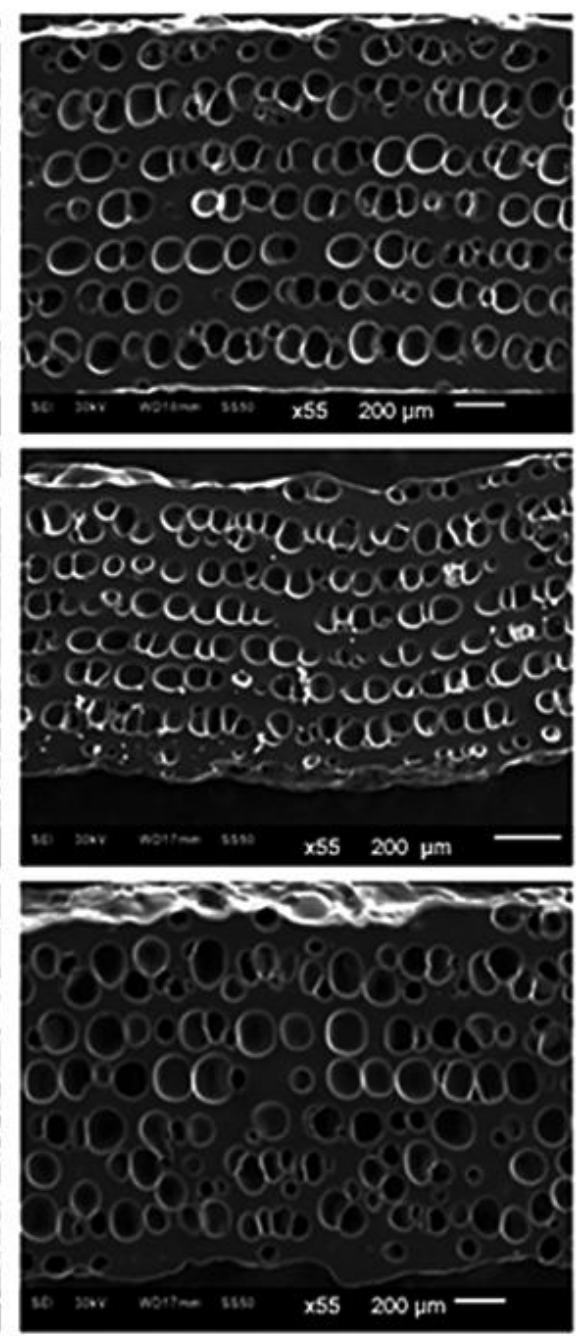

Film (MFI 4)/Foam (MFI8)
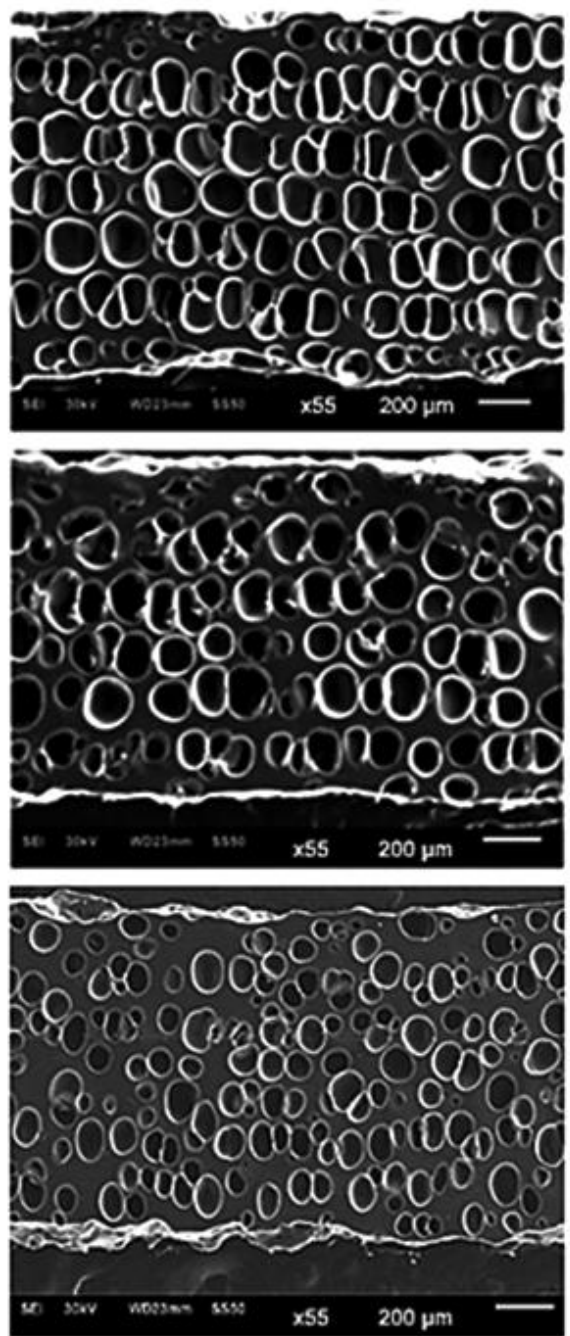

Fig. 7. SEM images showing the effect of foam content (50,70 and $80 \mathrm{v} \%$ ) and viscosity contrast between film and foam layers of 16 layers film/foam systems. Layered morphology is evident in each system. 

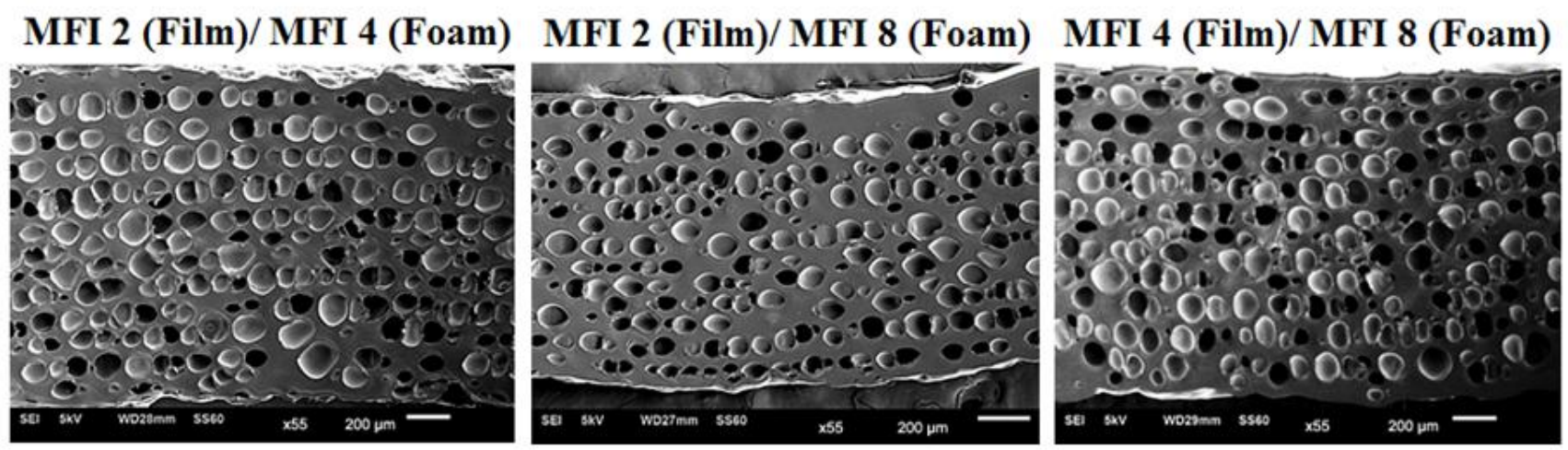

Fig. 8. SEM images showing the effect of viscosity contrast between film and foam layers on 32 layers film/foam (50/50) structures. 

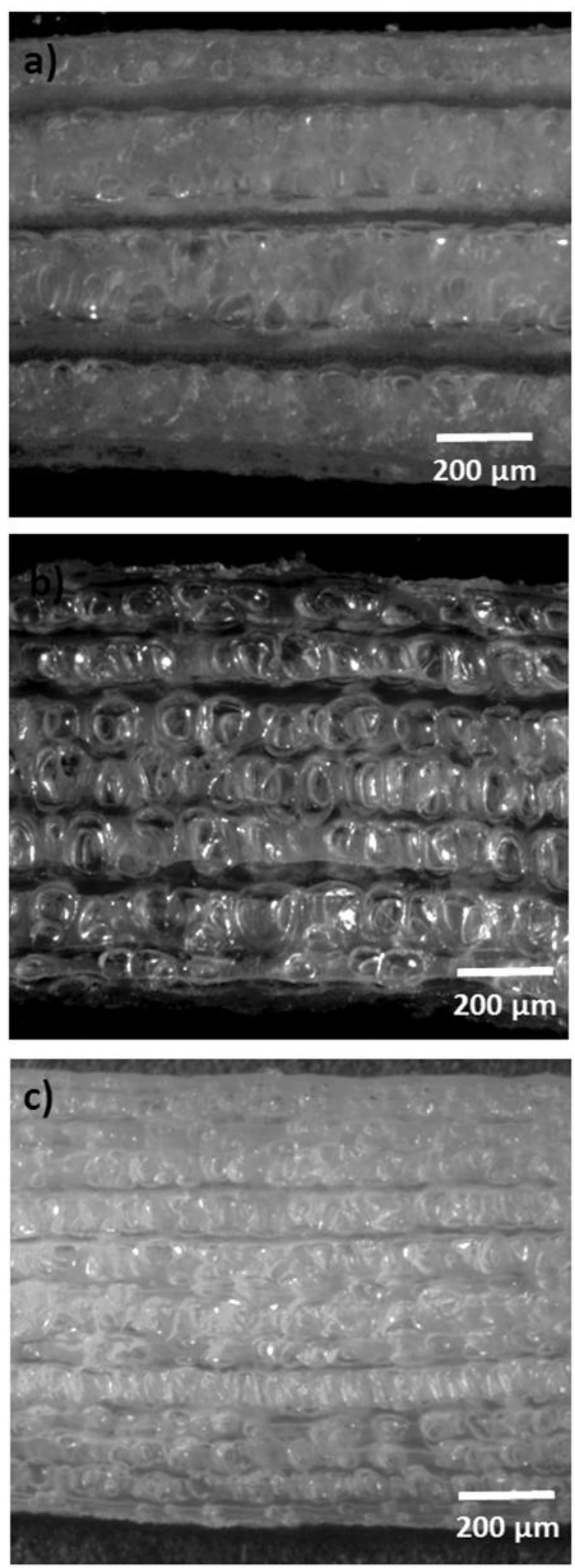

Fig. 9. Optical images showing the film/foam layered morphology of PP/LDPE systems having 8 (a), 16 (b) and 32 (c) layers. 


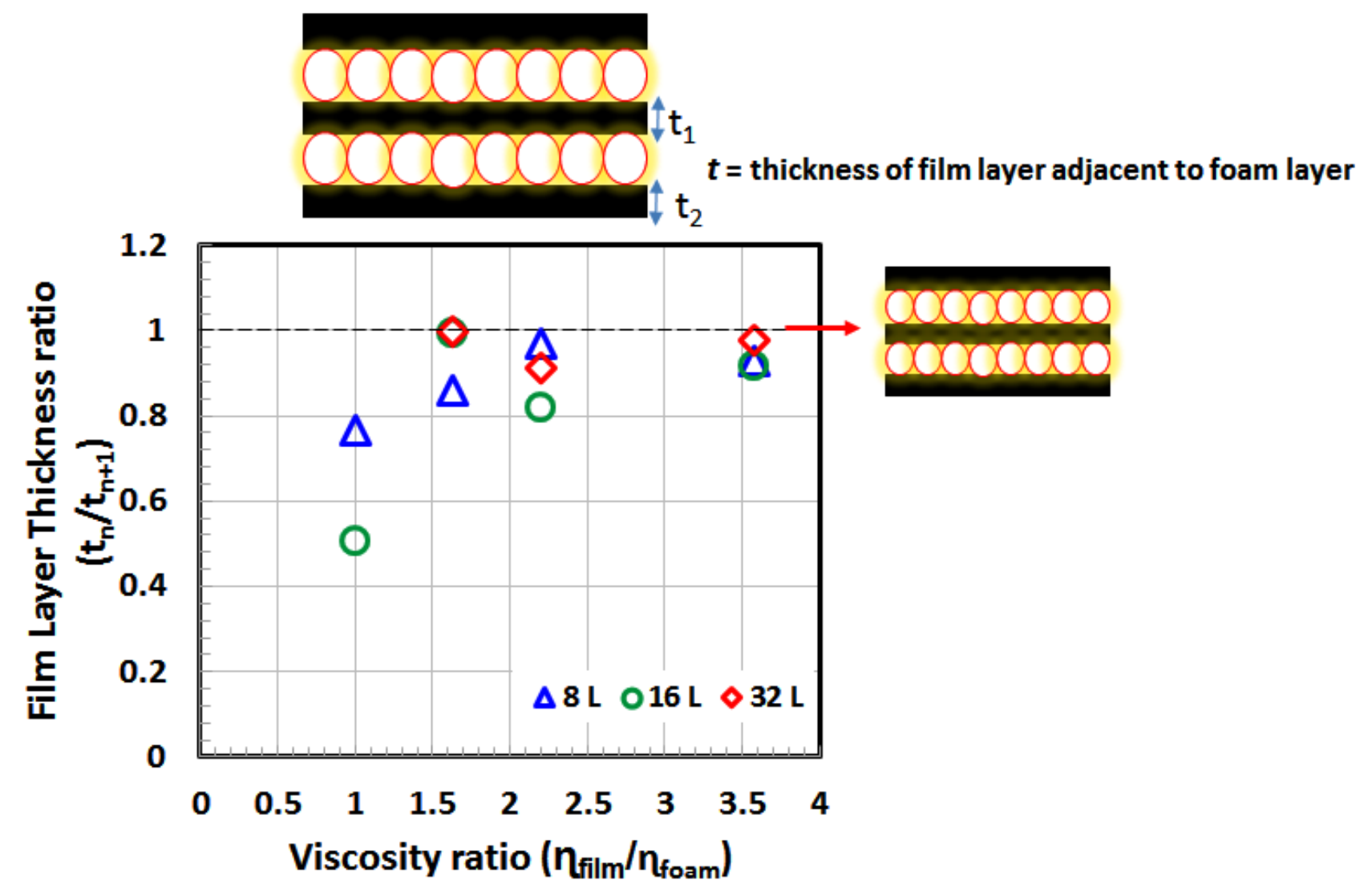

Fig. 10: Layer uniformity in different film/foam systems having viscosity contrast between film and foam layer LDPEs. This plot shows layer uniformity as a function of viscosity ratio and layer number in different film/foam (50/50) systems. Layer uniformity improves as the viscosity ratio increases between film and foam layers. 


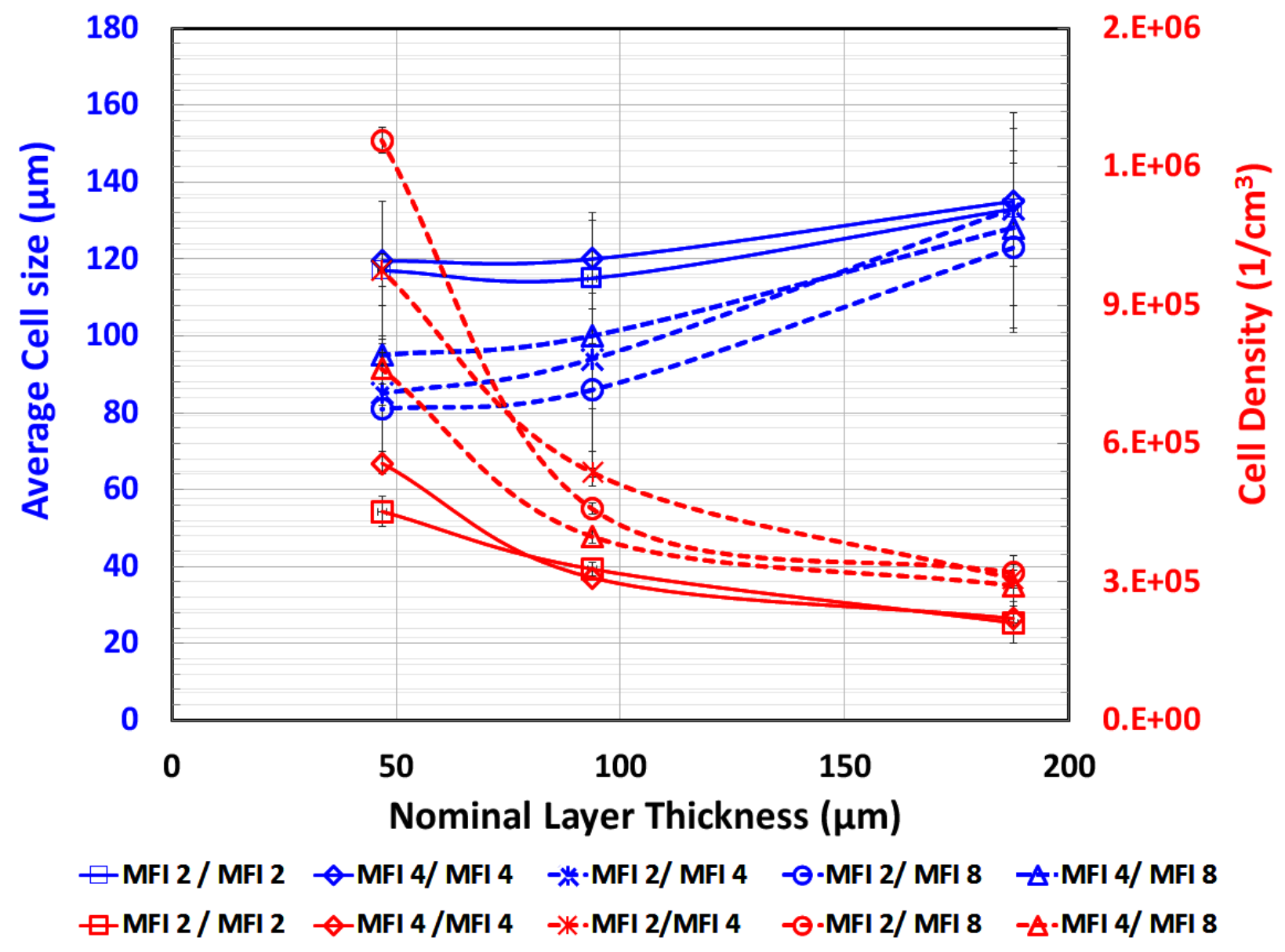

Fig. 11. Effect of layer thickness on the average cell size and cell density of film/foam (50/50) samples. This graph explains the confinement effect due to increasing the number of film layers that influences the cell density and cell size significantly. 

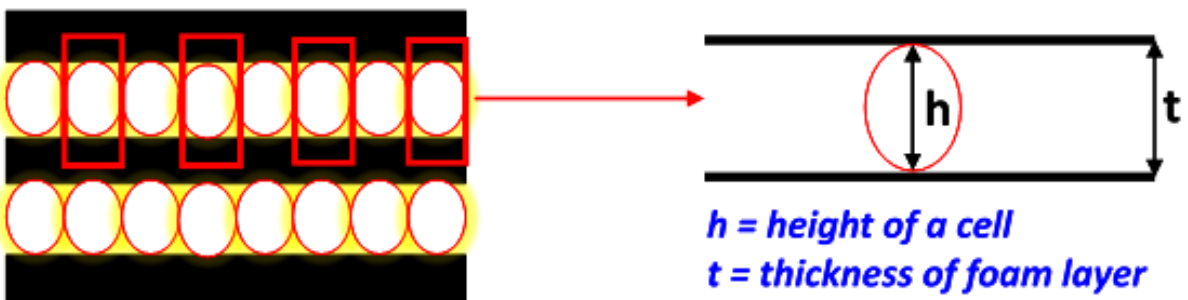

$h=$ height of $a$ cell

$t=$ thickness of foam layer

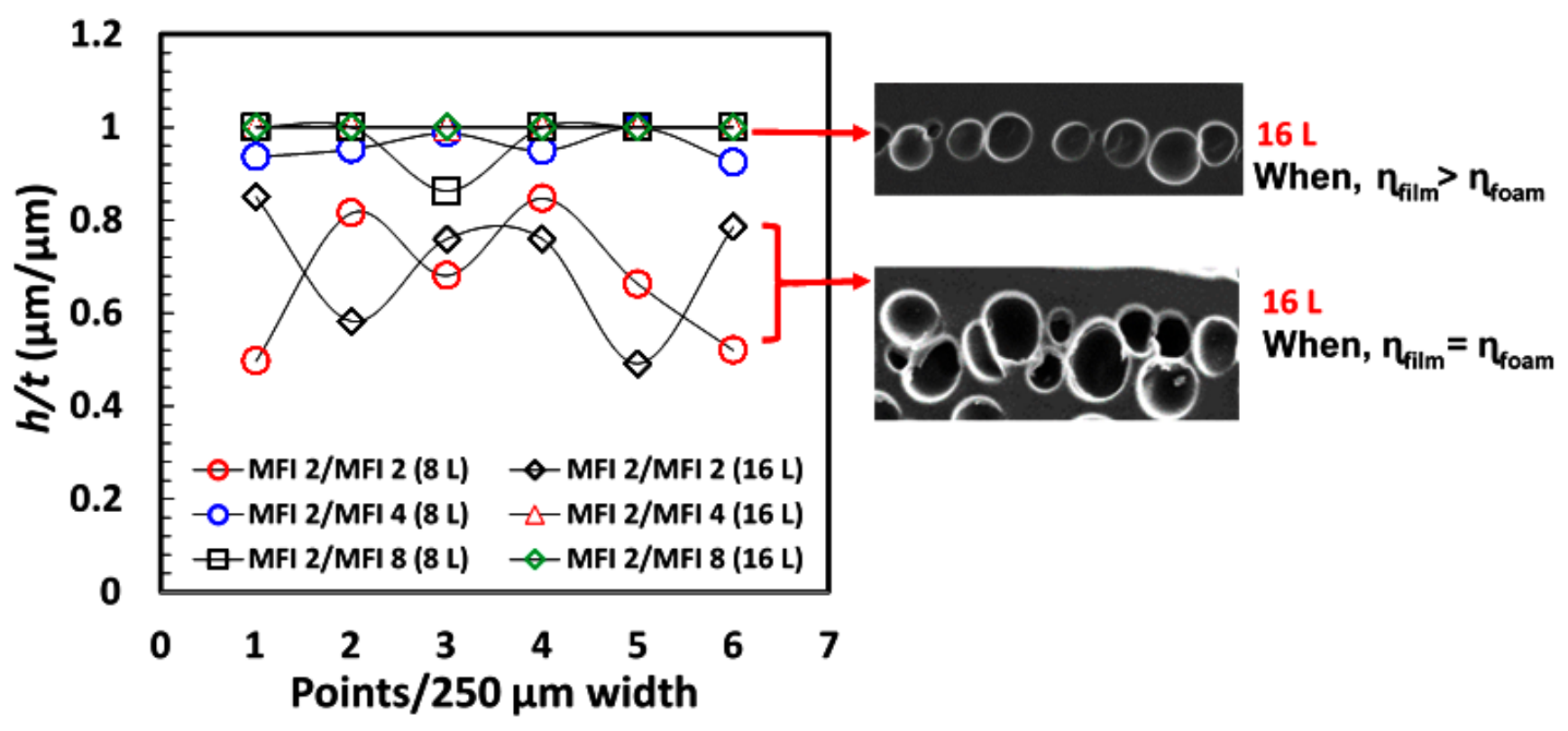

Fig. 12. Effect of viscosity contrast and layer number on the confinement of cells between film layers in each film/foam system. This graph shows that as the number of film layers increases, especially in viscosity contrast samples, the ratio between the height of cells and thickness of foam layers containing the cells, moves toward unity indicating the single cell alignment in foam layers. 

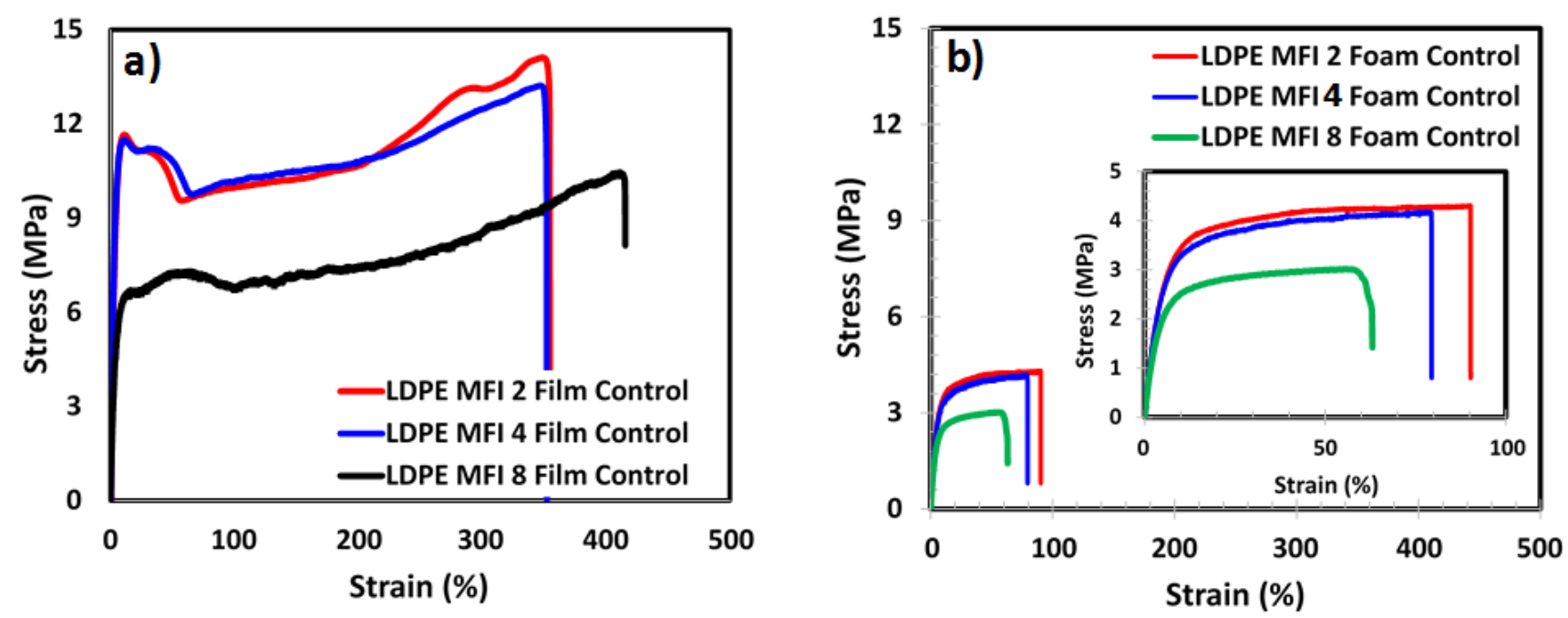

Fig. 13. Stress-strain behavior of LDPE films control (a) and foam controls (b). Note that in each film/foam systems LDPE with MFI 2 and MFI 4 have been used as the film layer polymers while MFI 2, MFI 4 and MFI 8 have been used as the foam layer polymers. It can be noticed that foaming of solid polymer led to the decrease in both strength and deformability of samples. 

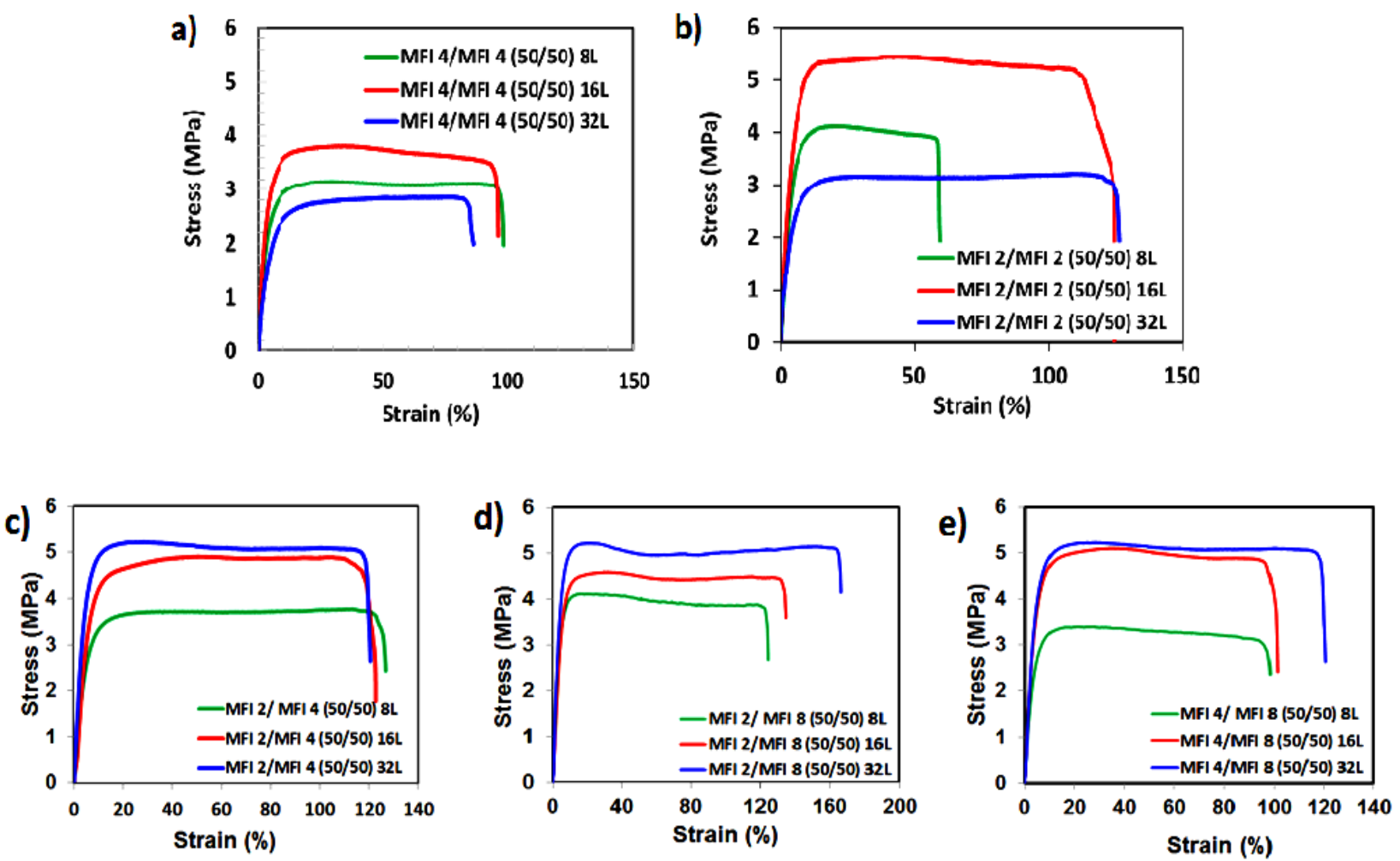

Fig. 14. Effect of layer number on the stress-strain behavior of LDPE/LDPE film/foam systems; (a) MFI 4/MFI 4, (b) MFI 2/MFI 2, (c) MFI 2/MFI 4, (d) MFI 2/MFI 8 and (e) MFI 4/MFI 8 film/foam systems. 


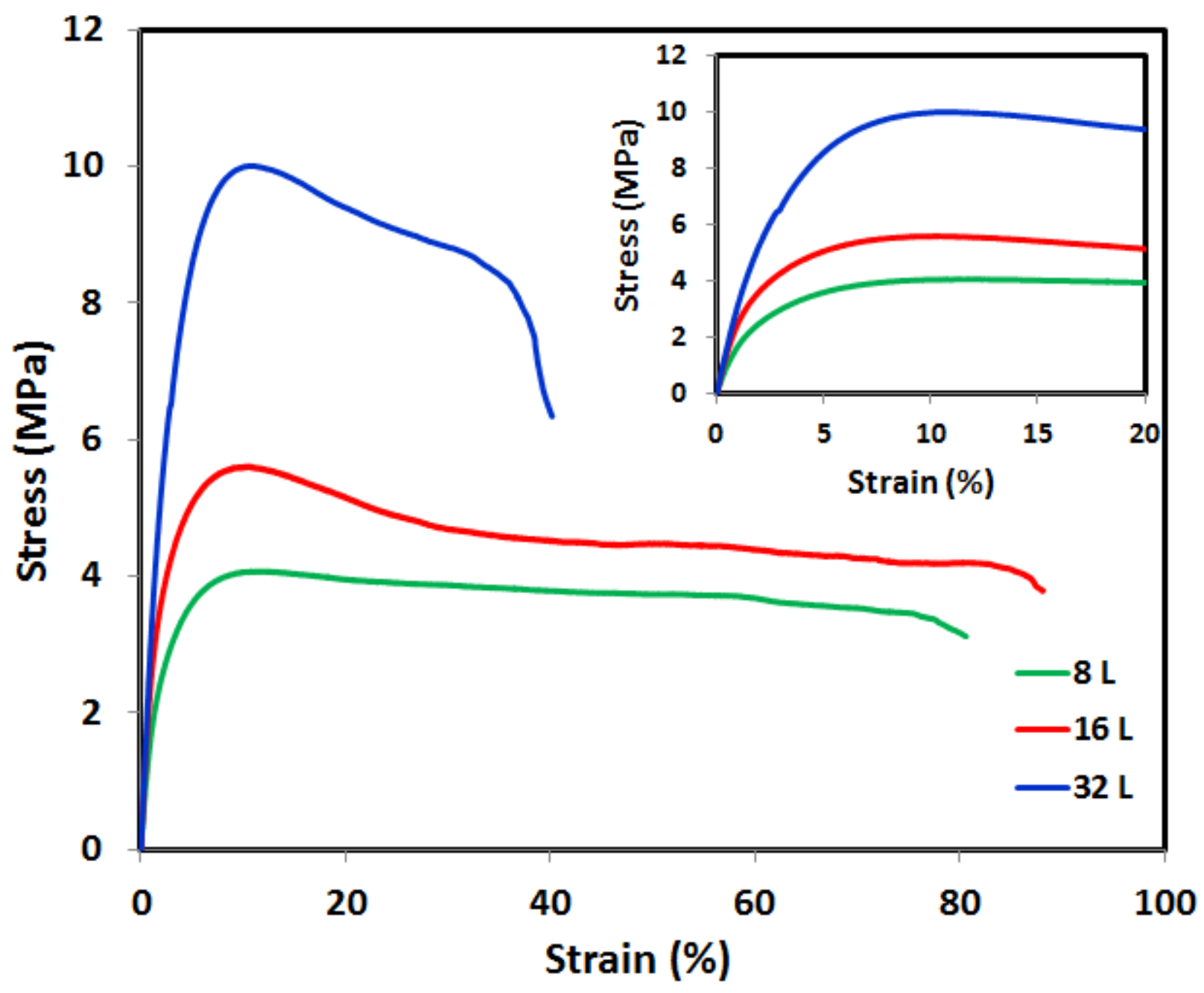

Fig. 15: Effect of layer number on the tensile stress-strain behavior of PP/LDPE (50/50) Film/Foam systems. 

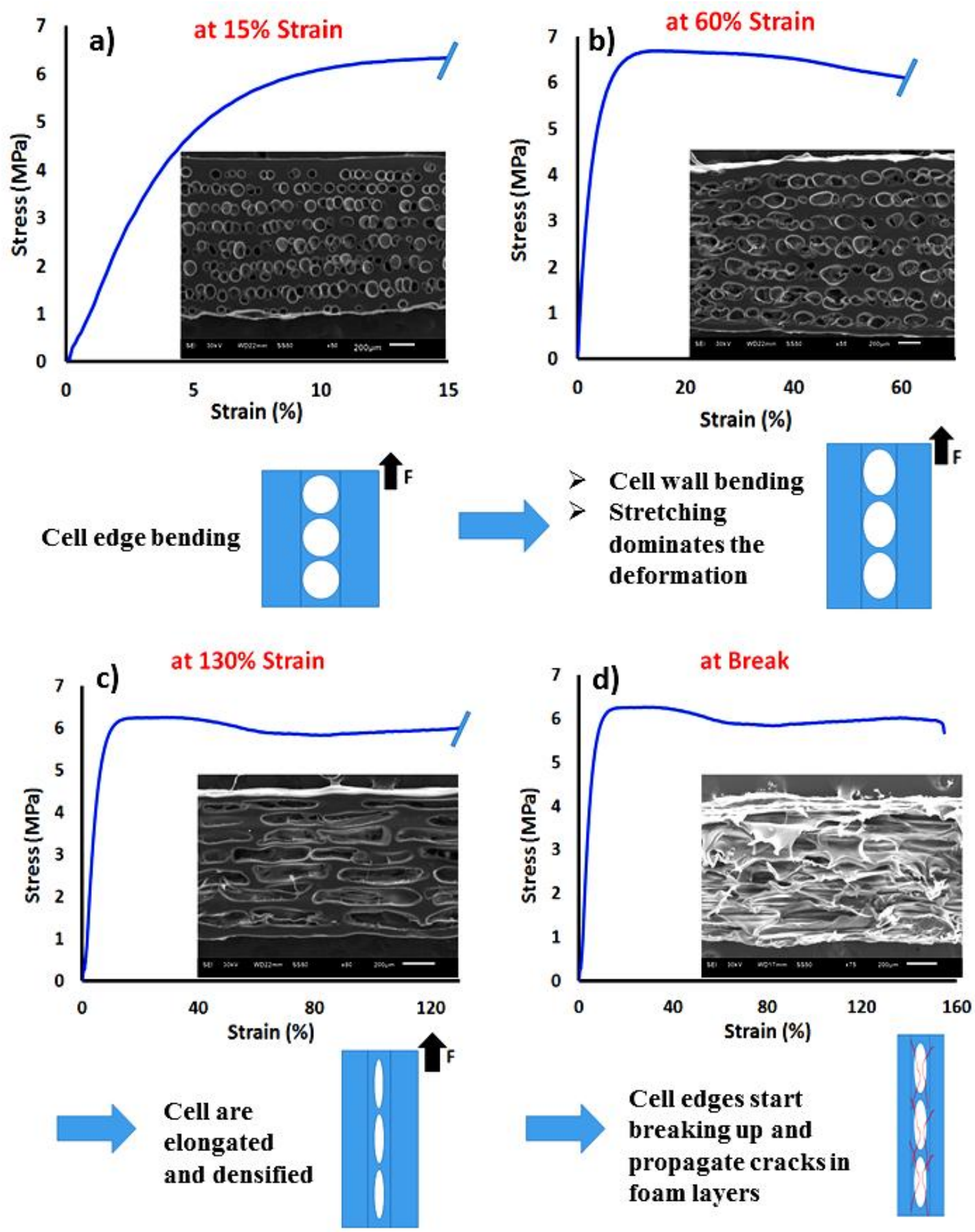

Fig. 16. Deformation mechanism of uniformly layered film/foam system. The SEM images showing the structural response to each level of deformation in tension. Note that $16 \mathrm{~L}$ film/foam (MFI 2/MFI 4) sample was studied here. 

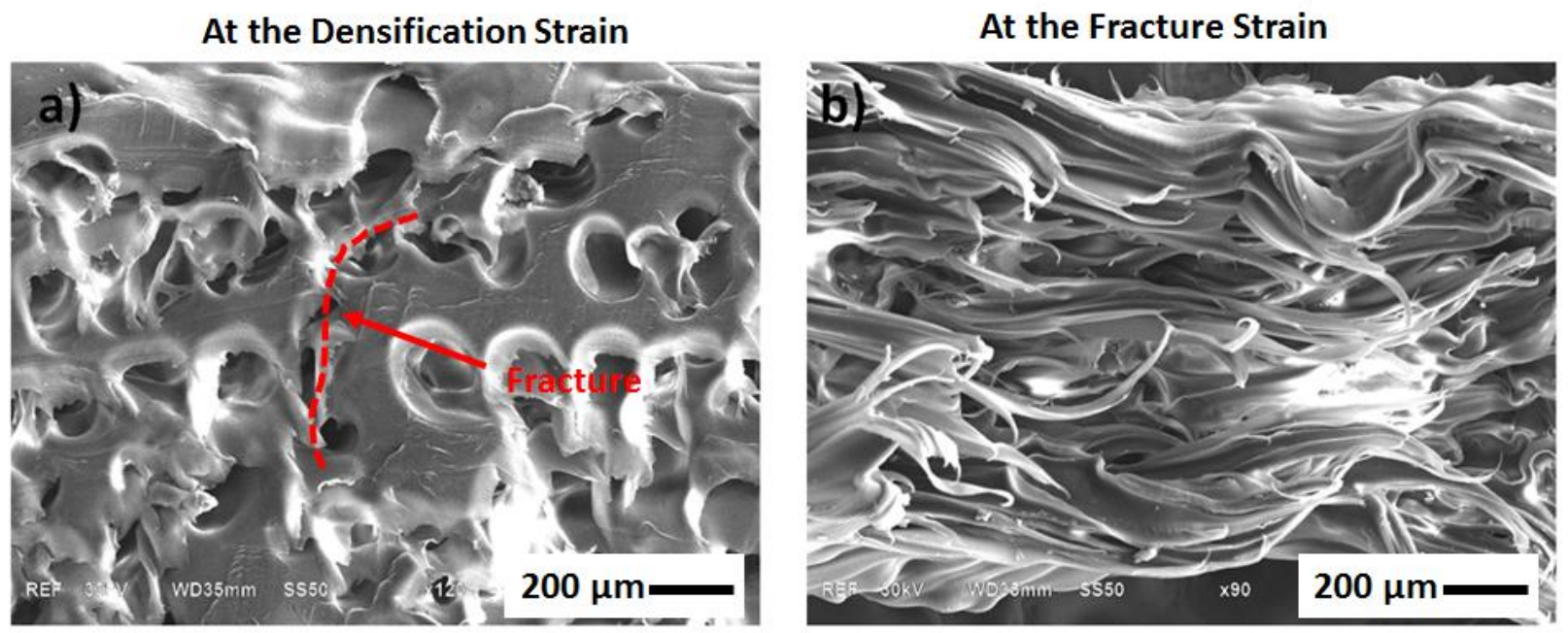

Fig. 17. SEM images showing the structural changes during tensile deformation in film/foam samples with no layer integrity (MFI 2/MFI 2, $32 \mathrm{~L}$ ); (a) at the densification strain and (b) at the fracture. 


\title{
Viscosity Contrast Effects on the Structure - Property Relationship of Multilayer Soft Film/Foams
}

\author{
Md. Arifur Rahman*, Ricardo Andrade, João Maia, Eric Baer
}

Center for Layered Polymeric Systems, Department of Macromolecular Science and

Engineering, Case Western Reserve University, Cleveland, OH 44106-7202, USA

Graphical Abstract

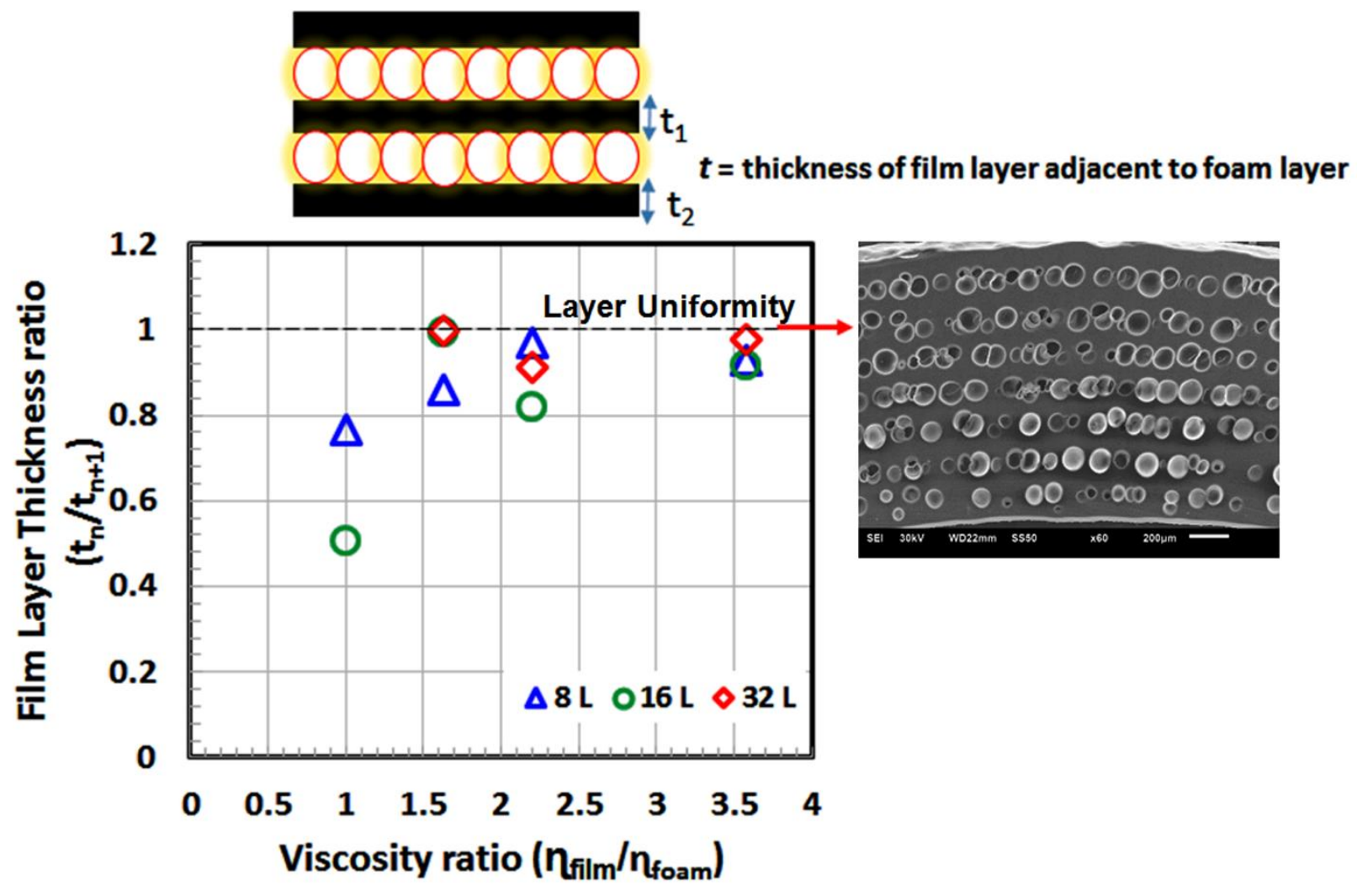

